\title{
Spatio-temporal variability of solid, total dissolved and labile metal: passive vs. discrete sampling evaluation in river metal monitoring
}

\author{
Cindy Priadi ${ }^{1}$, Adeline Bourgeault ${ }^{2}$, Sophie Ayrault ${ }^{1,{ }^{*}}$, Catherine Gourlay-Francé ${ }^{2}$, \\ Marie-HélèneTusseau-Vuillemin ${ }^{3}$, Philippe Bonté $^{1}$, Jean-Marie Mouchel ${ }^{4}$
}

\author{
${ }^{1}$ CEA-CNRS-UVSQ/IPSL - LSCE, Gif-sur-Yvette, 91190, France \\ ${ }^{2}$ Cemagref - Unité de recherche Hydrosystèmes et Bioprocédés, Antony, France ; \\ ${ }^{3}$ IFREMER, Issy-Les-Moulineaux, France ; \\ ${ }^{4}$ Université Pierre et Marie Curie - UMR, 7619 Sisyphe, Paris, France \\ *: Corresponding author : Sophie Ayrault, email address : sophie.ayrault@lsce.ipsl.fr
}

\begin{abstract}
:
In order to obtain representative dissolved and solid samples from the aquatic environment, a spectrum of sampling methods are available, each one with different advantages and drawbacks. This article evaluates the use of discrete sampling and time-integrated sampling in illustrating medium-term spatial and temporal variation. Discrete concentration index $(\mathrm{Cl})$ calculated as the ratio between dissolved and solid metal concentrations in grab samples are compared with time-integrated concentration index $(\mathrm{Cl})$ calculated from suspended particulate matter (SPM) collected in sediment traps and labile metals measured by the diffusive gel in thin films (DGT) method, collected once a month during one year at the Seine River, upstream and downstream of the Greater Paris Region. Discrete $\mathrm{Cl}$ at Bougival was found to be significantly higher than at Triel for $\mathrm{Co}, \mathrm{Cu}, \mathrm{Mn}, \mathrm{Ni}$ and $\mathrm{Zn}$, while discrete metal partitioning at Marnay was found to be similar to Bougival and Triel. However, when using timeintegrated $\mathrm{Cl}$, not only was Bougival $\mathrm{Cl}$ significantly higher than Triel $\mathrm{Cl}, \mathrm{Cl}$ at Marnay was also found to be significantly higher than $\mathrm{Cl}$ at Triel which was not observed for discrete $\mathrm{Cl}$ values. Since values are timeaveraged, dramatic fluctuations were smoothed out and significant medium-term trends were enhanced. As a result, time-integrated concentration index $(\mathrm{Cl})$ was able to better illustrate urbanization impact between sites when compared to discrete $\mathrm{Cl}$. The impact of significant seasonal phenomenon such as winter flood, low flow and redox cycles was also, to a certain extent, visible in time-integrated $\mathrm{Cl}$ values at the upstream site. The use of timeintegrated concentration index may be useful for medium- to long-term metal studies in the aquatic environment.
\end{abstract}




\section{Introduction}

In freshwater systems, metals are found as various forms ranging from cationic, inorganic, organometallic, sorbed on oxides and clay surfaces, metal alloys or incorporated in crystalline structures ${ }^{1-3}$. Defining all the metal forms (i.e. its speciation) in the water column is currently analytically difficult because it involves various forms in multiple pools. Yet, to illustrate and predict the environmental fate and transport of metal contaminants in this dynamic system, there is a need to investigate metal partitioning, and not just isolating specific phases ${ }^{4-6}$. One possible approach is to define metal partitioning as $\mathrm{Kd}$, a ratio between metal adsorbed in the solid fraction, operationally-defined as the filter-retained fraction $(>0.45 \mu \mathrm{m})$ and the metal concentration in the dissolved fraction $(<0.45 \mu \mathrm{m})$. $\mathrm{Kd}$ is often used in defining metal partitioning in the river system ${ }^{7-9}$. With relatively simple measurements, it may indicate a useful general view of metal distribution in the water column $^{10},{ }^{11}$ and the ability of the suspended particulate matter (SPM) to bind trace metals ${ }^{1}$.

$K_{d}$ is usually derived from discrete spot measurements. It is a parameter that may vary easily with even a slight fluctuation of dissolved fraction ${ }^{10}$ for which concentrations may oscillate 23 folds in urbanized water at the same location and is prone to analytical contamination ${ }^{1}$. Hence, $K_{d}$ is often considered to have limited predictive capability ${ }^{4}$. Alternatively, $K_{d}$ values can be empirically calculated as a function of water chemistry variables, using metal speciation models such as WHAM, SCAMP or MINTEQ ${ }^{11,12}$, although significant uncertainties were identified $^{4}$. 
Consequently, there is a need to explore other possibilities in-field metal partitioning that depend less on rapidly fluctuating physico-chemical parameters but are still responsive to medium and long-term water chemistry evolution and seasonal and spatial evolution. Discrete sampling-related problems may be solved by calculating partitioning using dissolved and particulate metal concentrations from time-weighted averaged samples. When deployment time is selected correctly, time-averaging samplers are able to measure changes of heavy-metal concentrations related to various physico-chemical parameters ${ }^{13,14}$. Inthe water column, time-integrated solid fractions may be sampled by sediment traps ${ }^{15,16}$. However, sampling of time-integrated dissolved fractions for metal analysis is currently difficult in practice. A possible approach is using in situ passive samplers. The diffusion gradient in thin films (DGT) technique was initially developed ${ }^{17}$ to quantitatively measure time-weighted average concentrations of labile metals in water. Tusseau-Vuillemin et al. ${ }^{18}$ and Buzier et al. ${ }^{19}$ then further developed the use of restrictive pore gels in DGTs, measuring labile metals composed of inorganic metals plus a fraction of easily exchangeable organic complexes that correlated with metal toxicity in Daphnia magna. With the combination of sediment traps and DGTs, it would then be possible to examine medium-term metal partitioning.

To what extent is metal partitioning obtained from time-averaged samples comparable and representative for spatial and temporal variations as opposed to those calculated from discrete samples? This paper aims to take a closer look at metal partitioning calculated from time-averaged and discrete samples and to evaluate their comparability in the need of robust and representative environmental monitoring parameters. It will also discuss how far these metal partitioning methods allow the study of urbanization impacts on metal behaviour in the water column. For the purpose of this study, suspended sediments are completely digested and thus metal concentration in the solid fraction includes not only adsorbed metals but also incorporated metals related to background geology. In order to avoid term confusion, this study will use concentration index (CI), defined as a ratio between metal concentration in the solid and metal concentration in the dissolved phase.

\section{Methodology}

\subsection{Study site}

For this work, samples were collected along the Seine River, France. The Seine River is located in a sedimentary basin in the north of France (Fig. 1), flowing through the Greater Paris Region. Before its estuary, the Seine River drains an area of $64700 \mathrm{~km}^{2}$ with an average density of 215 people $\mathrm{km}^{-2}$. It is an ideal example of an highly anthropized basin as it hosts 25\% of French agriculture, 30\% of French industry and 23\% of the French population $^{20}$. Previous studies have indicated a significant metal load within the watershed ${ }^{20-22}$, representative of multi-metal contamination in an urban catchment.

The sampling scheme aimed to distinguish the impacts of two sources of anthropogenic influence to the Seine River. The first source is the wastewater treatment plant (WWTP) Seine- Aval treating around 1.7 million $\mathrm{m}^{3}$ water per day ${ }^{23}$. The second is the area of greater Paris, including the most densely urbanized area in the region with more than 3700 inhabitants $\mathrm{km}^{-2} 24$.Treated municipal wastewater from smaller units and urban runoff are the major identified metal sources to the river in this area. The first sampling site is located at Marnay-sur-Seine, situated far upstream on the Seine River (Fig. 1). It was chosen to represent a site non-affected by the Greater Paris Region, where the Seine is a Strahler order 6 river, the population density upstream of Marnay is only 15- 30 inhabitants $\mathrm{km}^{-2} 24$. The second site is the Seine at Bougival, situated $40 \mathrm{~km}$ downstream of Paris city (Strahler order 7). It was chosen to demonstrate the impact of greater Paris without the influence of the major WWTP SeineAval. Another $40 \mathrm{~km}$ further downstream, Triel-sur-Seine was selected to demonstrate the influence of Greater Paris Region including all its inputs to the river. The Triel station is situated downstream of the confluent of the Seine River with one of its major tributaries, the Oise River, making it a Strahler order 8. Sampling was performed from October 2008 to October 2009. Unless mentioned otherwise, samples are collected around the $20^{\text {th }}$ of each month.

\subsection{Physico-chemical parameters}

$\mathrm{pH}$ was measured with either a pH meter WTW 330i (VWR) or a Waterproof pHtester 20 (Eutech Instruments) with a sensitivity of 0.05 . Temperature was continuously monitored with a temperature sensor (Hobo) with a sensitivity of $0.001^{\circ} \mathrm{C}$. Conductivity was measured in the laboratory within $6 \mathrm{~h}$ of field sampling with an Orion conductivity cell (Thermo). Daily discharge values were obtained from www.hydro.eaufrance.fr. Water was collected in plastic bottles for chlorophyll, pheopigment and ion analysis. Water was collected in $1 \mathrm{~L}$ precombusted glass bottles for dissolved organic carbon (DOC), TSS and particulate organic carbon (POC) analysis ${ }^{25}$. The absorbance at $254 \mathrm{~nm}$ (A254) of the GF-F filtrate was measured and the specific ultra-violet 
absorbance (SUVA) was calculated as SUVA $=$ A254/DOC in $\mathrm{cm}^{-1} \mathrm{~g}^{-1} \mathrm{~L}$. SUVA can be considered as an indicator of the aromaticity of dissolved organic matter (DOM $)^{26}$.

\subsection{Metal sampling and analysis}

Material and sample handling were performed following clean methodologies. All bottles and containers were soaked in $2 \mathrm{M} \mathrm{HNO}_{3}$ for at least 3 days. Afterwards they were rinsed thoroughly 3 times with de-ionised water. In the field, all bottles, buckets and containers were rinsed 3 times with river water. Sampling was done from the riverbank where a PVC bucket collected water around $3 \mathrm{~m}$ from the riverbank.

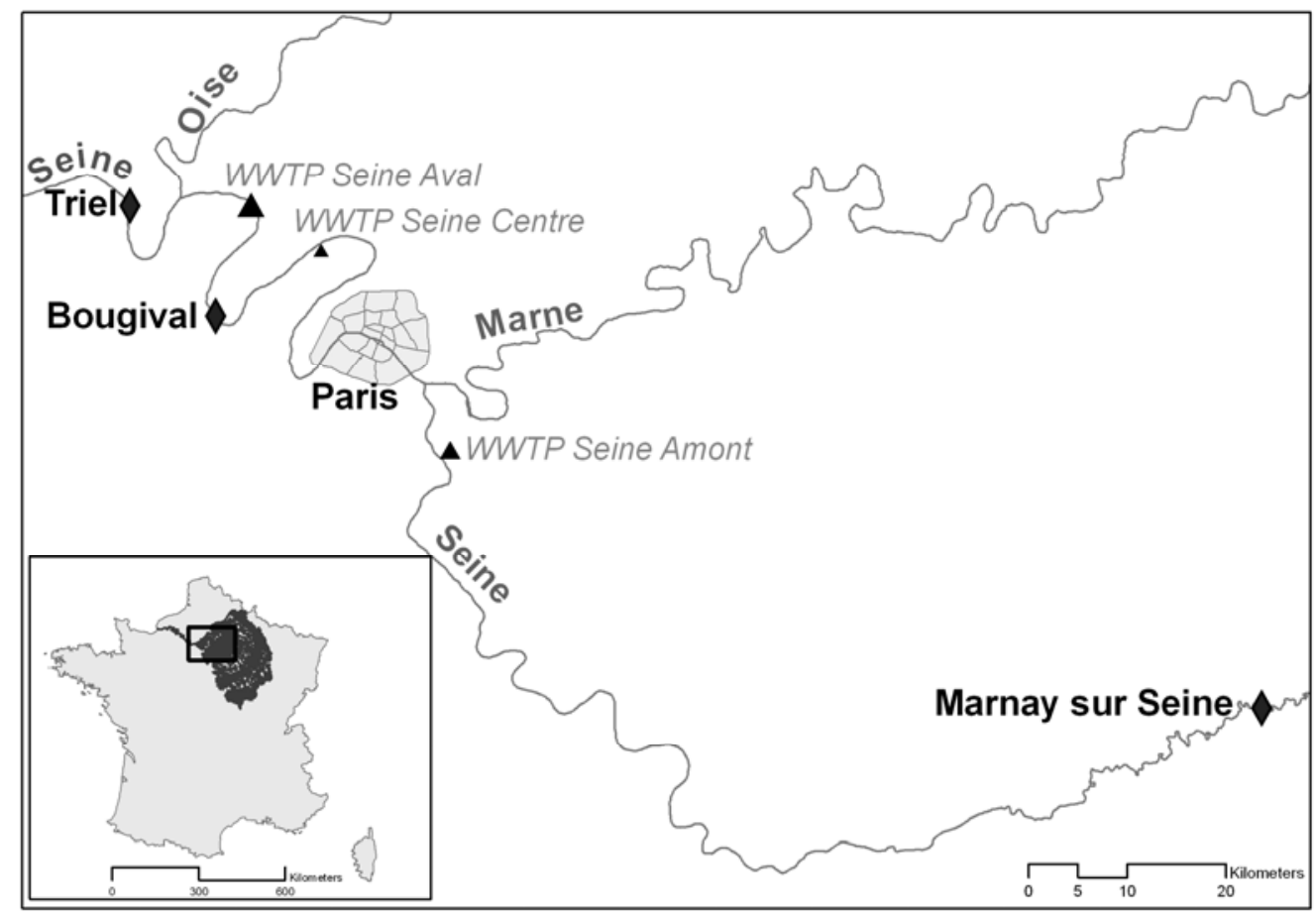

Figure 1 Sampling sites marked with diamonds; from upstream to downstream: Marnay sur Seine, Bougival and Triel. Black triangle indicates waste water treatment plants (WWTP) with triangle size indicating approximate treatment volume.

2.3.1. Dissolved fraction sampling. The dissolved $0.45 \mu \mathrm{m}$ fraction was obtained on-site by filtering with disposable Millex- LH Millipore syringe filters and $20 \mathrm{~mL}$ disposable syringe, acidified with pure $200 \mathrm{~mL} \mathrm{HNO}_{3} 65 \%$ (Merck Suprapur) to avoid any precipitation. Sterile disposable $50 \mathrm{~mL}$ polyethylene tubes, previously tested for clean handling, were used. All samples are transported and kept at $4^{\circ} \mathrm{C}$ in the dark before analysis.

2.3.2. Labile fraction sampling. Six diffusive gradient in thin films (DGT) were deployed in each site once a month in order to assess time-weighted average labile metal contamination. The method for assembling DGT is explained thoroughly elsewhere ${ }^{22}$. In brief, after passing through a $0.45 \mu \mathrm{m}$ polyethersulfone (PES) filter and a $0.4 \mu \mathrm{m}$ polycarbonate filter, labile metals diffuse through a restrictive diffusive gel layer $(0.8$ mm thickness) and are strongly bound by chelex resins. After DGT retrieval, they were brought back to the laboratory and the chelex resins were eluted in $1 \mathrm{M}$ nitric acid in which the analysis was performed. Labile metal concentrations were calculated according to the method detailed in Bourgeault et $\mathrm{al}^{27}$. The deployment duration was previously validated by Bourgeault et al. to avoid bio-fouling ${ }^{28}$.

2.3.3. Suspended particulate matter (SPM) sampling. For discrete SPM sampling, water was collected in $2 \mathrm{~L}$ polyethylene bottles, kept in the dark at $4^{\circ} \mathrm{C}$ and filtered in the laboratory $1-5$ days after sampling to minimize biological activity and SPM accumulation on the bottle walls. Only the September sample 
was filtered 1 month after sampling due to technical reasons. Filtration was performed on a $0.45 \mu \mathrm{m}$ Millipore MF-Millipore cellulose ester filter mounted on the Millipore filtration system (diameter $47 \mathrm{~mm}$ ). The sample bottle was vigorously shaken to ensure all SPM was evacuated during filtration. When possible, filtration was done on one filter, but in extreme cases where turbidity was high, filtration was done on two filters. Filters were weighted before and after filtration after drying at $40^{\circ} \mathrm{C}$ and stabilizing weight for up to 2 days in a desiccated jar.

A sediment trap was also installed at each site. It consisted of a 2L polyethylene terephtalate (PET) water bottle hung top-down at least $1 \mathrm{~m}$ from the river bank at mid-depth. Two holes (4 cm diameter) were cut on two opposite sides on the upper part of the bottle, and placed in the flow direction. This method was previously successfully used by Tessier ${ }^{14}$ to collect SPM in slow flowing rivers. After sampling, the total sediment trap content (water and SPM) was stored in the dark at $4^{\circ} \mathrm{C}$ before analysis. Storage duration ranged from 2-5 days for most samples to one month for the September sample. Samples were then centrifuged in the laboratory at $2800 \mathrm{~g}$ for $20 \mathrm{~m}$ and SPM was recovered. The SPM was then freeze-dried for at least $48 \mathrm{~h}$ and homogenized in an agate mortar.

All discrete SPM recovered on the filters and $0.1 \mathrm{~g}$ of time-integrated SPM from the sediment trap were totally digested using a method adapted for the Seine River carbonated $\mathrm{SPM}^{29,30}$, and allowing total SPM digestion. Details are presented in the ESI.† All solutions used were ultrapure reagents to assure minimum contamination ( $\mathrm{HNO}_{3}$ and $\mathrm{HCl}$ Normatom grade (VWR France), $\mathrm{HF}$ and $\mathrm{HClO}_{4}$ "for trace metal analyses", (Baker, Sodipro France)).

2.3.4. Trace metal analysis. Major and trace metal concentrations (Ag, Al, As, Ca, Cd, Cr, Co, $\mathrm{Cu}, \mathrm{Fe}, \mathrm{K}, \mathrm{Mg}, \mathrm{Mn}, \mathrm{Ni}, \mathrm{Se}, \mathrm{Ti}, \mathrm{Pb}, \mathrm{V}$, and $\mathrm{Zn}$ ) were determined in the dissolved fraction and digested SPM fraction using inductively coupled plasma quadrupolar mass spectrometry (ICP-QMS) (XIICCT-Series, ThermoElectron, France). The ICP-QMS spectrometer was calibrated using standard solutions and routinely checked with certified river water (SRM 1640, National Institute for Science and Technology, Gaithersburg, USA). Instrumental drifts and plasma fluctuations were corrected using internal standards (Re, Rh, and In (SPEX, SCP Science, France)) for all studied metals, and Ge for major elements including $\mathrm{Ca}$, Al, and Mg. To minimize isobaric interferences, analysis with collision cell technology (CCT) introducing a supplementary gas mixture of $\mathrm{H}_{2}$ (7\%) and $\mathrm{He}(93 \%)$ was applied for $\mathrm{Fe}, \mathrm{Mn}, \mathrm{Cd}, \mathrm{Cr}, \mathrm{Co}, \mathrm{Cu}, \mathrm{Mn}, \mathrm{Ni}, \mathrm{Pb}$, and $\mathrm{Zn}$ determination.

Overall, sampling representativeness and analytical accuracy was satisfactory. Ten dissolved fractions collected at one time in one site showed a standard deviation of $2 \%$ or less for $\mathrm{Co}, \mathrm{Mn}, \mathrm{Ni}, \mathrm{Pb}$ and $\mathrm{Zn}$; $5 \%$ for $\mathrm{Cu}$ and $9 \%$ for $\mathrm{Cr}$ and $\mathrm{Cd}$. Variation of labile metals recovered by DGT depended on time and metals. Standard deviation (SD) of the 6 DGT is displayed as ESI. $†$ Values obtained for the reference sediment SL1 (12 replicates) were compared to certified values, recovery was $90-99 \%$ for all analyzed elements except Cd (116\%), with a standard deviation of $10 \%$ or less for all elements except Mn with a SD of $18 \%$ and Cd with a SD of $24 \%$.

\subsection{Two-phase concentration index (CI) calculation}

Results and interpretation of two-phase concentration index (CI) was limited to 8 elements, Cd, Cr, Co, $\mathrm{Cu}, \mathrm{Mn}, \mathrm{Ni}, \mathrm{Pb}$ and $\mathrm{Zn}$, for which the ability for DGTs to estimate a one-month labile concentration has been validated ${ }^{27}$. "Discrete" CI $\left(10^{3} \mathrm{~L} \mathrm{~g}^{-1}\right)$ were calculated as the concentration ratio between metals in SPM $(>0.45 \mu \mathrm{m})$ to discrete dissolved metals $(<0.45 \mu \mathrm{m})$ both collected by discrete sampling (Eq (1)). Superscript $m$ refers to the month of sampling.

$$
\text { "Discrete" CI }=[\mathrm{Me}]_{\text {SolidMeas }}^{m} /[\mathrm{Me}]_{\text {DissMeas }}^{m} \text { Eq.1) }
$$

"Integrated" CI $\left(10^{3} \mathrm{~L} \mathrm{~g}^{-1}\right)$ were calculated as the concentration ratio between metal in SPM collected in the sediment trap to labile metal (DGT) both integrating one month of sampling. (Eq (2)). Integrated CI with superscript $m$ is based on integrated samples deployed between dates $m 1$ and $m$.

$$
\text { "Integrated" CI }=[\mathrm{Me}]_{\text {trap }}^{m} /[\mathrm{Me}]_{\text {labile }}^{m} \text { (Eq.2) }
$$

where $[M e]_{\text {Trap }}^{m}$ is the concentration of settleable sediment collected in the sediment trap deployed on month $m 1$ and collected on month $\mathrm{m}$ and $[\mathrm{Me}]_{\text {Labile }}^{m}$ is the concentration of labile metals measured by the DGT method trap deployed on month $m 1$ and collected on month $m$. 


\subsection{Labile-inert-solid partitioning}

Average metal proportion in the three different pools of the water column: labile metals measured by DGT, inert metals as the difference between labile and dissolved metals, and solid metals; were estimated. Due to different sampling methods for each pool (discrete vs. integrating) and variable quantification limits (much lower for labile metals via DGT than for total dissolved metals), a specific procedure was set to derive inert (non labile) dissolved metal concentrations. When

$$
\left([\mathrm{Me}]_{\text {DissMeas }}^{m-1}+[\mathrm{Me}]_{\text {DissMeas }}^{m}\right) / 2>[\mathrm{Me}]_{\text {labile }}^{m}
$$

Inert metal concentrations (Eq (3)) were calculated as thedifference between the averaged dissolved metal concentration (Eq (4)) and the labile metal concentration.

$$
\left([M e]_{\text {DissMeas }}^{m-1}+[M e]_{\text {DissMeas }}^{m} / 2<[M e]_{\text {Labile }}^{m}\right.
$$

where for month $m$, discrete dissolved metal concentration wereaveraged between measurements taken on month $m$ and the month before $(m-1)$.

$$
[\mathrm{Me}]_{\text {DissAvg }}^{m}=[\mathrm{Me}]_{\text {DissMeas }}^{m-1}+[\mathrm{Me}]_{\text {DissMeas }}^{m} / 2(\text { Eq.4) }
$$

When dissolved concentrations were lower than quantificationlimit (QL) and average dissolved concentration calculated from Eq (3) became lower than labile concentration, inert metals were considered as negligible in the balance and integrated labile metals were considered as a relevant proxy for integrated total dissolved metals (Eq (5)).

$$
\begin{gathered}
{[\mathrm{Me}]_{\text {DisAvg }}^{m}=[\mathrm{Me}]_{\text {labile }}^{m} \text { (Eq.5) }} \\
\text { when }\left([\mathrm{Me}]_{\text {DissMeas }}^{m-1}+[\mathrm{Me}]_{\text {DissMeas }}^{m}\right) / 2<[\mathrm{Me}]_{\text {labile }}^{m} \text { Total solid metal, defined as total solid metal per }
\end{gathered}
$$
liter of water, was obtained by multiplying metal content $\left(\left(\mu \mathrm{g} \mathrm{g}^{-1}\right)\right.$ of each month with SPM concentration $\left(\mathrm{g} \mathrm{L}^{-1}\right)$. Average solid metal $\left(\mu \mathrm{g} \mathrm{L}^{-1}\right)$ for month $\mathrm{m}\left([\mathrm{Me}]_{\text {SolidAvg }}^{m}\right)$ was then calculated similarly to the calculation of the average dissolved concentration in Eq (3).

Total metal $\left(\mu \mathrm{g} \mathrm{L}^{-1}\right)$ was calculated as a sum between the average solid metal and dissolved metal concentration, both in $\mu \mathrm{g} \mathrm{L}^{-1}$ (Eq.6).

$$
[\mathrm{Me}]_{\text {Total }}^{m}=[\mathrm{Me}]_{\text {DisAvg }}^{m}+[\mathrm{Me}]_{\text {SolidAvg }}^{m} \text { (Eq.6) }
$$

Distribution of metal in each phase (labile, inert and solid) was then calculated using the total metal calculated using Eq.(6).

\section{Results}

In order to optimally present data of monthly variation, median values were used. Comparisons between samples were performed using Mann-Whitney ranked tests $(\mathrm{p}=0.01)$.

\subsection{River chemistry}

Table 1 Summary of measured physico-chemical parameters during 13 months of sampling between 20082009 indicating minimum-maximum values with 1st quartile - median - 3rd quartile in parenthesis; Q: discharge; DOC: dissolved organic carbon; SPM: suspended particulate matter; POC: particulate organic carbon (n=13) 


\begin{tabular}{|c|c|c|c|}
\hline & Marnay & Bougival & Triel \\
\hline $\mathrm{Q}(\mathrm{m} 3 / \mathrm{s})$ & $25-89(37-50-54)$ & $92-324(116-184-215)$ & $198-550(225-340-384)$ \\
\hline $\mathrm{pH}$ & $8.06-8.32(8.14-8.18-8.28)$ & $7.20-8.24(7.76-7.91-8.09)$ & $7.10-8.01(7.58-7.73-7.85)$ \\
\hline Alkalinity (mg/L) & 152.5 - $286.7(218.08-237.9-262.3)$ & 182 - 281 (224 - 244 - 259) & $189-281(236-253-264)$ \\
\hline Conductivity $(\mu \mathrm{S} / \mathrm{cm})$ & $268-526(387-479-499)$ & $449-611(490-527-570)$ & $506-668(588-619-655)$ \\
\hline Temperature $\left({ }^{\circ} \mathrm{C}\right)$ & $5.6-23(7-13.1-17.1)$ & $4.5-22.8(8.5-15.2-19.9)$ & $4.9-22(8.9-14.4-19.2)$ \\
\hline Chlorophyll ( $\mu \mathrm{g} / \mathrm{L})$ & $0.5-3.5(0.7-1.0-1.7)$ & $0.4-15.1(2.7-3.7-8.1)$ & $0.3-16.4(2.1-2.5-7.9)$ \\
\hline DOC (mg/L) & $1.62-2.68(1.83-2.05-2.38)$ & $2.56-4.34(2.77-2.94-3.25)$ & $3.42-5.45(3.72-3.87-3.97)$ \\
\hline $\mathrm{Ca}^{2+}(\mathrm{mg} / \mathrm{L})$ & $58.01-105.35(72.36-88.27-93.19)$ & $73-100(80-95-98)$ & $77-109(89-99-102)$ \\
\hline $\mathrm{Mg}^{2+}(\mathrm{mg} / \mathrm{L})$ & $0.54-8.93(3.28-3.97-4.66)$ & $0.64-10.3(3.45-6.4-7.03)$ & $0.68-8.63(5.79-7.34-8.12)$ \\
\hline $\mathrm{K}^{+}(\mathrm{mg} / \mathrm{L})$ & $1.55-6.26(1.93-2.06-3.28)$ & $0.42-4.61(2.49-3.36-4.19)$ & $1.54-9.18(3.79-4.32-5.55)$ \\
\hline $\mathrm{Na}^{+}(\mathrm{mg} / \mathrm{L})$ & $3-20(6-8-9)$ & $6.7-17.7(12.6-14.9-16.1)$ & $10.4-27.5(15.3-19.5-22.2)$ \\
\hline $\mathrm{Cl}^{-}(\mathrm{mg} / \mathrm{L})$ & $11-27(13-14-20)$ & $17.4-34.2(23.9-26.6-30.1)$ & $19.9-41.9(34-37-41.2)$ \\
\hline $\mathrm{NH}_{4}^{+}(\mathrm{mg} / \mathrm{L})$ & $0.3-1.4(0.4-0.6-1)$ & $0.09-2.92(0.17-0.41-0.74)$ & $0.23-4.28(0.38-0.51-1.39)$ \\
\hline $\mathrm{NO}_{3}{ }^{-}(\mathrm{mg} / \mathrm{L})$ & $7.8-26(11.3-18-24.9)$ & 13.2 - $26.7(15.1$ - 21.3 - 25) & $20.2-35.2(27.9-28.5-31.3)$ \\
\hline $\mathrm{SO}_{4}{ }^{2-}(\mathrm{mg} / \mathrm{L})$ & $13.7-22.4(14.3-17.3-18.8)$ & $24.4-44.6(31.1-36.1-38.4)$ & $28-51.5(43.6-46.4-49.5)$ \\
\hline SPM (mg/L) & $4.1-21.9(7.8-9.8-11.9)$ & $6.4-44.1(8.5-10.9-15.7)$ & 4.0 - $33.4(5.7-9.5-19.4)$ \\
\hline POC (mg/L) & $0.05-1.9(0.42-0.56-0.9)$ & $0.38-3.92(0.69-0.88-1.03)$ & $0.04-2.47(0.72-0.89-1.08)$ \\
\hline $\mathrm{Ca}(\%)$ & $13.9-44.2(17.0-17.8-18.7)$ & $7.2-15.5(11.6-12.1-12.7)$ & 4.0 - 30.8 (9.1 - 9.7 - 10.1) \\
\hline $\mathrm{Fe}(\%)$ & $0.65-2.87(1.53-1.84-2.20)$ & $1.42-3.26(2.35-2.62-2.91)$ & $0.29-5.17(2.40-2.78-3.09)$ \\
\hline $\mathrm{Al}(\%)$ & $0.4-4.77(2.22-3.10-3.41)$ & $1.19-5.30(2.69-4.06-4.55)$ & $0.25-8.47(3.02-3.80-3.94)$ \\
\hline $\mathrm{Mg}(\mathrm{mg} / \mathrm{kg})$ & $158-12227(2661-3382-3970)$ & $3515-19076(4429-5766-8270)$ & 1397 - 8815 (4965 - 5462 - 7656) \\
\hline $\mathrm{K}(\mathrm{mg} / \mathrm{kg})$ & $183-9478(5288-7306-8088)$ & $2726-11946(7317-8883-10320)$ & $1446-17945(7944-9052-9885)$ \\
\hline
\end{tabular}

Most water quality parameters measured throughout the campaign displayed a Marnay-Bougival-Triel gradient indicating evident evolution in water chemistry (Table 1). The $\mathrm{pH}$ at the upstream site is relatively more basic, $\mathrm{pH} 8.20 \pm 0.04$, where the river drains calcareous rocks. As the catchment becomes more urbanized, $\mathrm{pH}$ drops to $7.91 \pm 0.04$ and $7.73 \pm 0.04$ downstream at Bougival and Triel, respectively. Downstream sites had significantly higher values of DOC and POC and higher photosynthetic activities indicated by higher chlorophyll concentration. Major ions showed two different trends; Ca and $\mathrm{NH}_{4}{ }^{+}$concentrations remained constant at the 3 sites, while the others increased downstream. From upstream to downstream, the median of magnesium and potassium ion concentrations doubled, while chloride and sulfate increased by a factor of 2.5.

Median metal concentrations in different pools in the water column showed an evident upstreamdownstream increasing trend from Marnay to Bougival and Triel, although in general, Bougival displayed higher metal content than Triel for all except Co and Mn (Table 2). The dilution effect of the confluence between the Seine and the Oise River (25 km downstream from Bougival and $15 \mathrm{~km}$ upstream from Triel-sur-Seine) may be the cause of the decrease in metal concentration in Triel.

Table 2 Summary of metal concentration at the three studied sites in four measured phases indicating minimum-maximum values with 1st quartile - median - 3rd quartile in parenthesis $(n=13)$ 


\begin{tabular}{|c|c|c|c|c|c|}
\hline & & & Marnay & Bougival & Triel \\
\hline \multirow{4}{*}{ Cd } & \multirow{2}{*}{ Grab } & $<0.45 \mu \mathrm{m}(\mu \mathrm{g} . \mathrm{L}-1)$ & $<\mathrm{LQ}$ & $0-0.015(0-0-0.013)$ & $0-0.019(0.012-0.013-0.014)$ \\
\hline & & $>0.45 \mu \mathrm{m}(\mu \mathrm{g} . \mathrm{g}-1)$ & $0-4.42(0.43-0.54-1.05)$ & $0.77-20.53(1.69-2.47-4.05)$ & $0.44-2.29(0.88-1.41-2.06)$ \\
\hline & \multirow{2}{*}{ time integrated } & Labile DGT $\left(\mu \mathrm{g} . \mathrm{L}^{-1)}\right.$ & $0-0.002(0.001-0.001-0.001)$ & $0-0.007(0.002-0.003-0.005)$ & $0-0.005(0.003-0.004-0.005)$ \\
\hline & & sed.trap $(\mu \mathrm{g} . \mathrm{g}-1)$ & $0.269-0.444(0.294-0.309-0.332)$ & $1.53-8.07(1.73-2.65-3.57)$ & $0.35-3.03(0.85-1.23-1.86)$ \\
\hline \multirow{4}{*}{$\mathrm{Cr}$} & Grab & $<0.45 \mu \mathrm{m}(\mu \mathrm{g} . \mathrm{L}-1)$ & $0-1.086(<\mathrm{LQ})$ & $0-1.041(0-0-0.508)$ & $0-1.235(0-0.212-0.324)$ \\
\hline & & 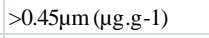 & $7.7-101.7(41.9-53.6-64.8)$ & $46.3-102.4(73-84.2-88.9)$ & 35.9 - $121.9(58.1$ - 69.1 - 88.1) \\
\hline & time integrated & Labile DGT ( $\mu$ g.L-1) & $0-0.035(0.018-0.02-0.025)$ & $0-0.093(0.024-0.028-0.035)$ & $0-0.086(0.025-0.031-0.037)$ \\
\hline & & sed.trap ( $\mu$ g.g-1) & 42.1 - $54.2(50$ - 50.5 - 51.4) & 69.2 - $109.3(71.3$ - 85.4 - 96.4) & 56.4 - 86.7 (65 - 73.5 - 80.9) \\
\hline \multirow{4}{*}{ Co } & \multirow{2}{*}{ Grab } & $<0.45 \mu \mathrm{m}(\mu \mathrm{g} . \mathrm{L}-1)$ & $0.04-0.18(0.09-0.12-0.16)$ & $0.13-0.25(0.17-0.21-0.23)$ & $0.2-0.39(0.26-0.3-0.32)$ \\
\hline & & $>0.45 \mu \mathrm{m}$ ( $\mu \mathrm{g} . \mathrm{g}-1)$ & $2.48-9.17(6.49-7.59-8.52)$ & $6.42-38.4(10.75-11.51-12.7)$ & $5.9-25.2(10.9-14-17.5)$ \\
\hline & \multirow{2}{*}{ time integrated } & Labile DGT ( $\mu$ g.L-1) & $0-0.022(0.006-0.012-0.019)$ & $0-0.051(0.016-0.023-0.042)$ & $0-0.078(0.029-0.038-0.057)$ \\
\hline & & sed.trap ( $\mu g . g-1)$ & $5.76-7.13(6.44-6.68-6.87)$ & $8.25-11.81(9.1-9.79-11.2)$ & $7.69-13.04(9-10.33-11.76)$ \\
\hline \multirow{4}{*}{$\mathrm{Cu}$} & \multirow{2}{*}{ Grab } & $<0.45 \mu \mathrm{m}(\mu \mathrm{g} . \mathrm{L}-1)$ & $0.27-0.67(0.35-0.37-0.46)$ & $0.77-1.76(1.02-1.12-1.27)$ & $0.8-1.56(1.07-1.22-1.45)$ \\
\hline & & $>0.45 \mu \mathrm{m}(\mu \mathrm{g} . \mathrm{g}-1)$ & $5.7-95.5(18.7-19.4-28)$ & 44.7 - $169.3(67.9-103.9$ - 147) & $21.1-130.3(56.2-72.2$ - 93.6) \\
\hline & \multirow{2}{*}{ time integrated } & Labile DGT ( $\mu$ g.L-1) & $0-0.104(0.062-0.074-0.085)$ & $0-0.481(0.172-0.253-0.298)$ & $0-0.388(0.21-0.251-0.307)$ \\
\hline & & sed.trap ( $\mu$ g.g-1) & 13.5 - $18.1(15.3-16.1$ - 17.2) & 78.8 - 185.3 (90.2 - 121.7 - 150.1) & $53.4-96.8(56-81.8-88.9)$ \\
\hline \multirow{4}{*}{$\mathrm{Mn}$} & \multirow{2}{*}{ Grab } & $<0.45 \mu \mathrm{m}(\mu \mathrm{g} . \mathrm{L}-1)$ & $1.44-3.19(1.81-2.43-2.6)$ & $3.07-17.39(7.01-8.3-10.75)$ & $4.37-27.63(11.62-15.38-17.67)$ \\
\hline & & $>0.45 \mu \mathrm{m}(\mu \mathrm{g} \cdot \mathrm{g}-1)$ & 130 - $910(394-444-761)$ & 514 - $1762(817-1035$ - 1186) & 484 - $2314(1097$ - 1428 - 1911) \\
\hline & \multirow{2}{*}{ time integrated } & Labile DGT ( $\mu$ g.L-1) & $0-3.21(0.41-1.13-2.24)$ & 0 - $8.38(2.27-3.72-7.18)$ & 0 - $10.23(4.45-4.71-9.65)$ \\
\hline & & sed.trap ( $\mu$ g.g-1) & 268 - $527(317$ - 431 - 452) & $281-1825(492-637-653)$ & 414 - $966(502-594$ - 872) \\
\hline \multirow{4}{*}{$\mathrm{Ni}$} & \multirow{2}{*}{ Grab } & $<0.45 \mu \mathrm{m}(\mu \mathrm{g} . \mathrm{L}-1)$ & $0.48-1.93(0.8-1.45-1.59)$ & $0.94-2.25(1.48-1.76-1.98)$ & $1.49-2.74(1.96-2.17-2.36)$ \\
\hline & & $>0.45 \mu \mathrm{m}(\mu \mathrm{g} . \mathrm{g}-1)$ & 9.1 - $83.5(20.5$ - 25.4 - 32) & $20.9-40.5(26.3-32.1$ - 36) & 0 - $59.5(21.5$ - 30.1 - 39.5) \\
\hline & \multirow{2}{*}{ time integrated } & Labile DGT ( $\mu$ g.L-1) & $0-0.212(0.135-0.173-0.202)$ & $0-0.47(0.228-0.322-0.419)$ & $0-0.796(0.443-0.543-0.578)$ \\
\hline & & sed.trap ( $\mu$ g.g-1) & 20.5 - $26.2(20.6$ - 21.3 - 21.6) & $26.2-40.2(28.4-31.3-37.4)$ & 21.2 - $30.7(25.2-27.7$ - 29.3) \\
\hline \multirow{4}{*}{$\mathrm{Pb}$} & \multirow{2}{*}{ Grab } & $<0.45 \mu \mathrm{m}(\mu \mathrm{g} . \mathrm{L}-1)$ & $0-0.071(<\mathrm{LQ})$ & $079-0.255(0.152-0.195-0.23$ & $0-0.327(0.145-0.162-0.204)$ \\
\hline & & 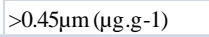 & $1-69(29-36-47)$ & $71-307(118-139-161)$ & $34-145(82-109-115)$ \\
\hline & \multirow{2}{*}{ time integrated } & Labile DGT ( $\mu$ g.L-1) & $0-0.031(0.004-0.007-0.011)$ & $0-0.161(0.024-0.032-0.058)$ & $0-0.039(0.018-0.019-0.023)$ \\
\hline & & sed.trap ( $\mu$ g.g-1) & 18.7 - $23.5(19.7$ - 20.2 - 21.7) & 80 - $245.2(93.3$ - 123 - 155.2) & 50.7 - $98.5(58.7$ - 81.8 - 84.1) \\
\hline \multirow{4}{*}{$\mathrm{Zn}$} & \multirow{2}{*}{ Grab } & $<0.45 \mu \mathrm{m}(\mu \mathrm{g} . \mathrm{L}-1)$ & 0 - $9.768(0-2.257-2.611)$ & 3.28 - $24.11(4.39-6.22-7.35)$ & $3.47-14.6(4.53-6.72-9)$ \\
\hline & & $>0.45 \mu \mathrm{m}(\mu \mathrm{g} \cdot \mathrm{g}-1)$ & 45 - $713(134-185$ - 395) & $336-671(383-480-567)$ & $43-1402(256-351-434)$ \\
\hline & \multirow{2}{*}{ time integrated } & Labile DGT ( $\mu \mathrm{g} . \mathrm{L}-1)$ & $0-1.488(0.159-0.444-0.756)$ & $0-3.13(1.51-1.83-2.47)$ & $0-3.74(1.55-2.68-3.06)$ \\
\hline & & sed.trap ( $\mu$ g.g-1) & $106-149(110-120-126)$ & 307 - $694(406$ - 506 - 544) & 225 - $415(249$ - 342 - 395) \\
\hline
\end{tabular}

Dissolved metal concentrations compared with other rivers with strong urban influence showed that the Seine River dissolved concentrations (Table 2) are higher but are still in the same order of magnitude. Data found during this campaign were also comparable to other dissolved metal concentrations earlier reported in the Seine River $^{31}$. Labile metal concentrations of $\mathrm{Co}, \mathrm{Cu}, \mathrm{Mn}$ and Ni were within the range of those measured in the Seine River basin ${ }^{26}$. Concentrations of metals in SPM collected by discrete sampling were much more variable than those measured in SPM collected with the sediment trap on a monthly basis. Median values between the two sets were comparable. When metal concentrations in SPM were normalized by background geological values obtained from numerous sites in the Seine River basin, 32 SPM collected downstream at Bougival and Triel showed an average enrichment of 2-3 times for Ni, Cr and Co, 7-8 times for $\mathrm{Pb}, \mathrm{Cu}$ and $\mathrm{Zn}$, and 15-18 times for Cd.

\subsection{Labile-inert-solid partitioning}

Partitioning of each metal in the defined phases varied according to metals and sites (Fig. 2). The approach described in Eq (2)-(6) consisted of averaging discrete total metal for the dissolved and solid phases causing the total median values of the three phases displayed in Fig. 2 to be occasionally less or more than $100 \%$ of the total metal calculated through Eq (6). This is mainly true for Cd, Mn and $\mathrm{Zn}$ that displayed high variation of discrete concentrations to which this averaging method may constitute uncertainties of total partitioning of around 5-10\%. Nevertheless, averaged median values were considered representative because $\mathrm{Co}, \mathrm{Cr}, \mathrm{Cu}, \mathrm{Ni}$ and $\mathrm{Pb}$ showed total averages close to $100 \%$. 

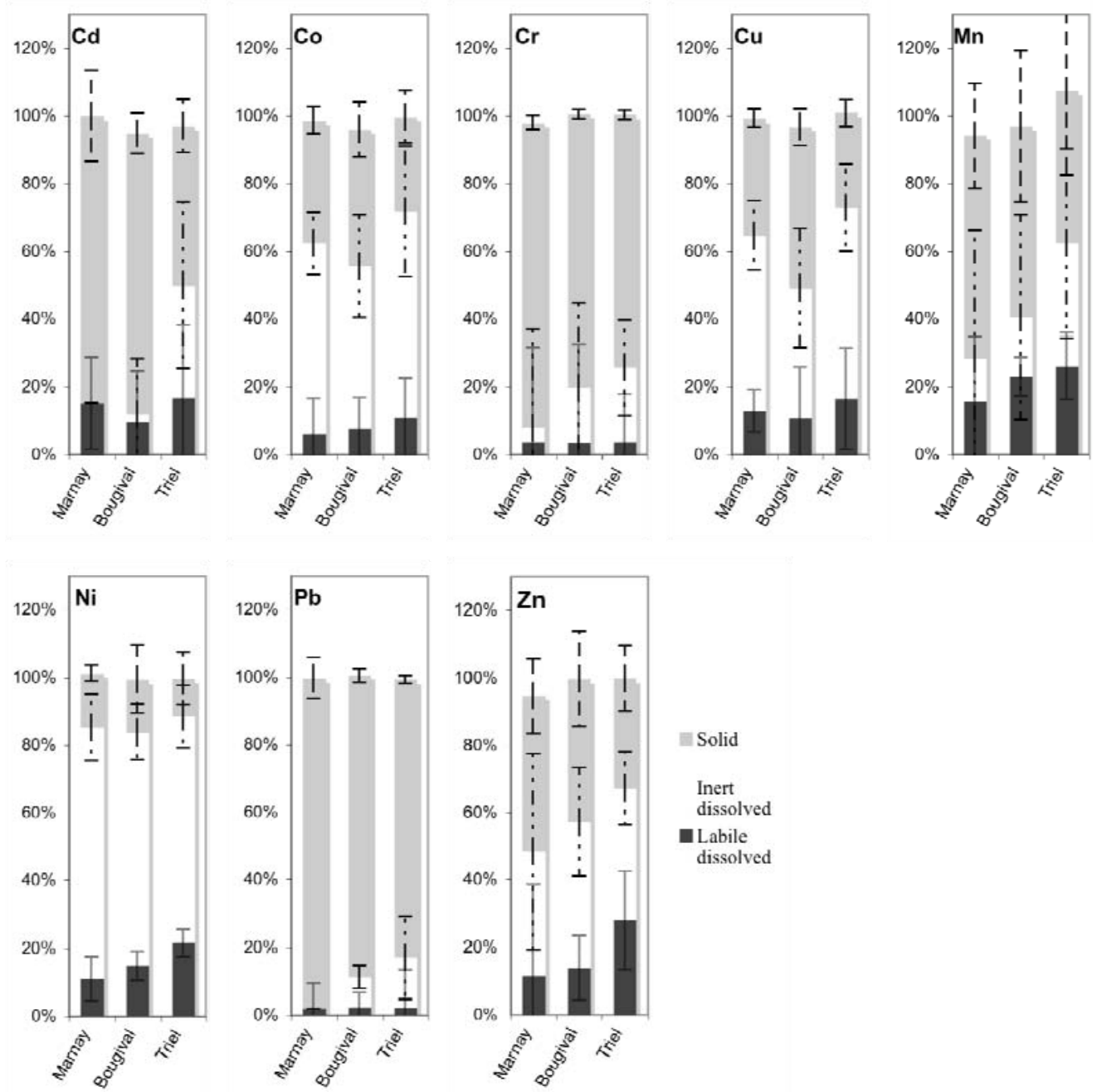

Figure 2. Bar charts represent average proportion of metal in each pool relative to the total of metal in the three defined pools. Individual labile dissolved metals were measured by DGT. Discrete inert dissolved metals were calculated from the average of dissolved metals for two months between the deployment and the collection of DGT subtracted by the labile metal pool. When labile metals were larger than the average dissolved metals, the dissolved metal pool was represented by concentration in the labile pool. Individual solid metals were calculated from the average of dissolved metals for two months between the deployment and the collection of DGT $(n=12)$.

Despite complete digestion of particulate metals, the proportion of dissolved metals in these samples was relatively high compared to literature data. Our data showed that for most metals, the median proportion of dissolved metal in the water column exceeded more than $50 \%$. Nguyen et al. found $\mathrm{Zn}$, Co, Cd and $\mathrm{Pb}$ in a contaminated lake highly associated to the solid phase (for about $70 \%$ of the total metal load) ${ }^{9}$. Previous metal partitioning values on the Seine River accounted for higher solid fraction (70 to 90\%) mostly due to relatively high approximation of SPM concentration used to theoretically calculate total solid metal ${ }^{24}$. Nevertheless, our dissolved and particulate metal data were in agreement with other Seine reference data ${ }^{31,33}$, indicating that calculated CI was fairly accurate despite differences with other water bodies.

\subsection{Two-phase concentration index (CI)}

Metals were ranked by their preference to the solid phase using the average discrete $\mathrm{CI}$ indicating $\mathrm{Pb}>$ $\mathrm{Cr}>\mathrm{Mn} \sim \mathrm{Cd}>\mathrm{Zn}>\mathrm{Cu} \sim \mathrm{Co}>\mathrm{Ni}$ (Table 3). When time-integrated CI is compared, a similar order is observed for most of the metals, except for $\mathrm{Co}$ and $\mathrm{Cu}$ that moved up the ranking: $\mathrm{Pb}>\mathrm{Cr}>\mathrm{Cd}>\mathrm{Co}>\mathrm{Cu}>\mathrm{Zn}>\mathrm{Mn}>\mathrm{Ni}$. Most studies display logarithmic CI values but for this study, basic CI was chosen to better observe the fluctuations in metal partitioning. 
Table 3 Summary of metal partitioning at the three studied sites (in L.g ${ }^{-1)}$, “discrete CI" is the ratio between concentration of a given metal in the solid fraction to the dissolved fraction (water collected by discrete sampling and filtered at $0.45 \mathrm{\mu m}$ ) and "time-integrated $\mathrm{CI}$ " is the ratio between concentration of a given metal in the settleable suspended particles collected by a sediment trap to the labile fraction measured with the Diffusive Gradient Thin (DGT) films. Indicated values correspond to minimum-maximum values with 1st quartile - median - 3rd quartile in parenthesis ( $n=13$ for "discrete $\mathrm{CI}$ " and $\mathrm{n=10}$ for "Time-integrated CI). QL: quantification limit.

\begin{tabular}{|c|c|c|c|c|}
\hline & & Marnay & Bougival & Triel \\
\hline \multirow{2}{*}{ Cd } & "Discrete" CI & $<Q L$ & $118-590(196-284-339)$ & $64-169(83-116-145)$ \\
\hline & "Time-integrated" CI & $236-936(316-364-522)$ & $497-3591(647-859-1160)$ & 131 - 595 (168 - 414 - 567) \\
\hline \multirow{2}{*}{$\mathrm{Cr}$} & "Discrete" CI & $28-301(80-132-216)$ & 70 - $325(167-186-240)$ & $47-415(131-230-276)$ \\
\hline & "Time-integrated" CI & $1422-3256(1687-2334-2868)$ & $1425-4461(2292-2914-3628)$ & 712 - $9420(1565-2586-3326)$ \\
\hline \multirow{2}{*}{ Co } & "Discrete" CI & $26-204(43-52-87)$ & $31-224(48-51-78)$ & $23-129(39-45-50)$ \\
\hline & "Time-integrated" CI & 302 - 1766 (345 - 532 - 1028) & $222-760(336-519-703)$ & $99-452(132-252-376)$ \\
\hline \multirow{2}{*}{$\mathrm{Cu}$} & "Discrete" CI & $16-269(41-52-103)$ & $52-166(58-102-115)$ & 21 - $103(42-52-85)$ \\
\hline & "Time-integrated" CI & $153-277(174-202-241)$ & $349-831(473-513-567)$ & $223-469(242-258-300)$ \\
\hline \multirow{2}{*}{ Mn } & "Discrete" CI & $79-553(163-189-345)$ & 49 - 337 (62 - 133 - 189) & $37-505(61-93-114)$ \\
\hline & "Time-integrated" CI & $132-1665(158-331-973)$ & 74 - 887 (97 - 164 - 249) & $49-208(60-96-128)$ \\
\hline \multirow{2}{*}{$\mathrm{Ni}$} & "Discrete" CI & $6-73(13-18-42)$ & $11-43(13-19-22)$ & $0-30(11-14-20)$ \\
\hline & "Time-integrated" CI & $97-221(110-121-147)$ & $75-218(87-113-128)$ & $41-66(48-51-55)$ \\
\hline \multirow{2}{*}{$\mathrm{Pb}$} & "Discrete" CI & $654-654(654-654-654)$ & $424-1325(701-881-945)$ & $217-749(483-563-634)$ \\
\hline & "Time-integrated" CI & 718 - $5644(1577-2543-4023)$ & 2698 - 9863 (3992 - 4459 - 5044) & $1494-9509(2803-4593-5593)$ \\
\hline \multirow{2}{*}{$\mathrm{Zn}$} & "Discrete" CI & $19-577(53-100-171)$ & $17-165(46-94-109)$ & $5-360(29-50-71)$ \\
\hline & "Time-integrated" CI & $100-1064(143-158-413)$ & $205-872(250-291-536)$ & $60-172(119-144-156)$ \\
\hline
\end{tabular}

The CI for each month in the three sites was also individually compared in order to evaluate spatial evolution (Fig. 3). Discrete CI at Bougival was found to be significantly higher than at Triel $(p=0.011)$ for all metals except for $\mathrm{Cd}, \mathrm{Cr}$ and $\mathrm{Pb}$ which were excluded from the comparison because many dissolved concentration values at Marnay were lower than the quantification limit (QL). Nevertheless, no difference was found between discrete metal partitioning at Marnay when compared to Bougival and Triel ( $p>0.05)$ because CI variation at Marnay was very high. When the same test was applied to time-integrated CI, values at Bougival were also found to be significantly higher than at Triel ( $\mathrm{p}$ 0.0001). Moreover, CI at Marnay was also found to be significantly higher than CI at Triel $(\mathrm{p}<0.0002)$, which was not observed for discrete CI values. As time-integrated CI had lower detection limits, $\mathrm{CI}$ for $\mathrm{Cd}, \mathrm{Cr}$ and $\mathrm{Pb}$ were better defined for Marnay. When this statistical comparison was performed on all elements without excluding $\mathrm{Cd}, \mathrm{Cr}$ and $\mathrm{Pb}$, similar conclusions were obtained. 


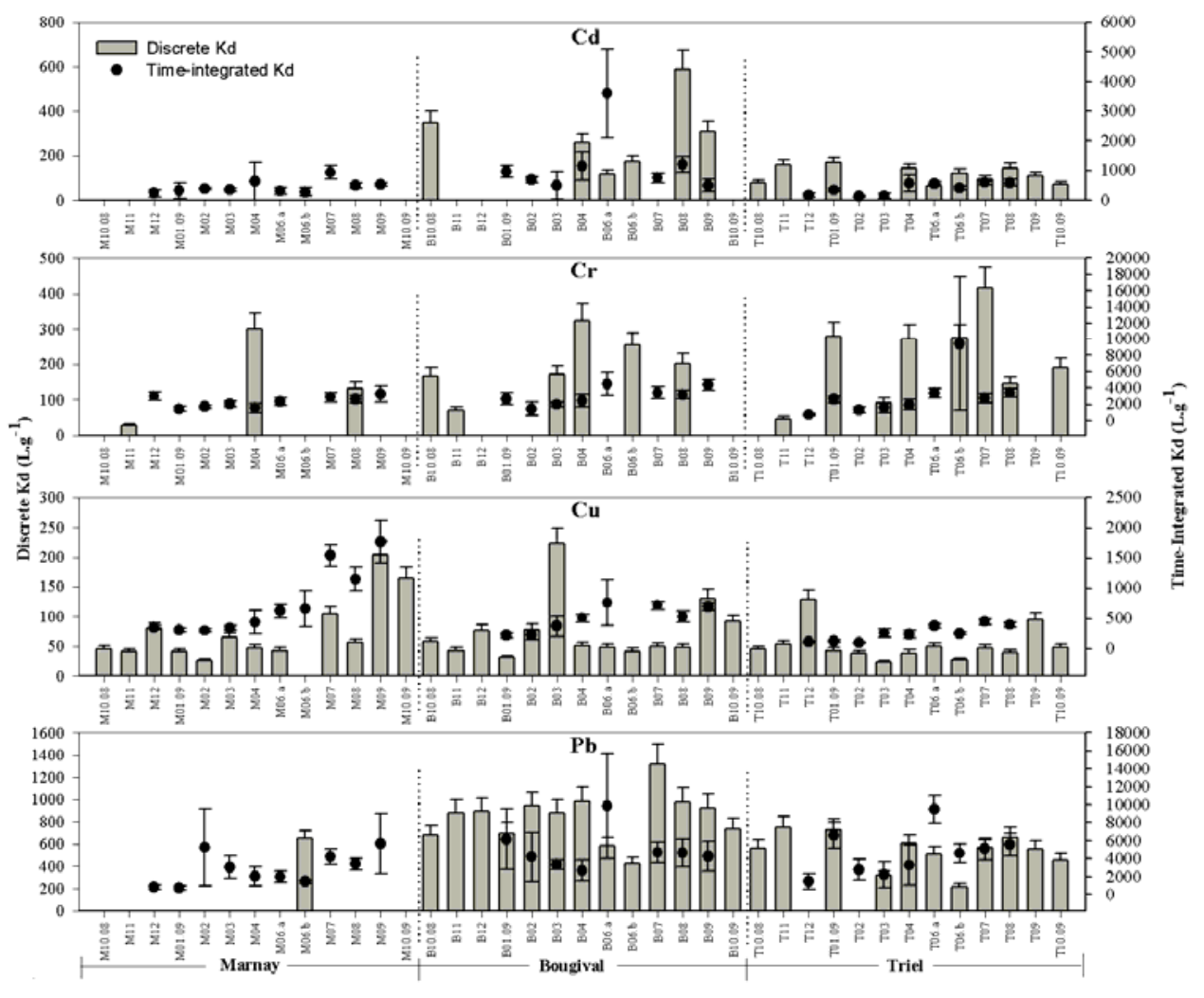




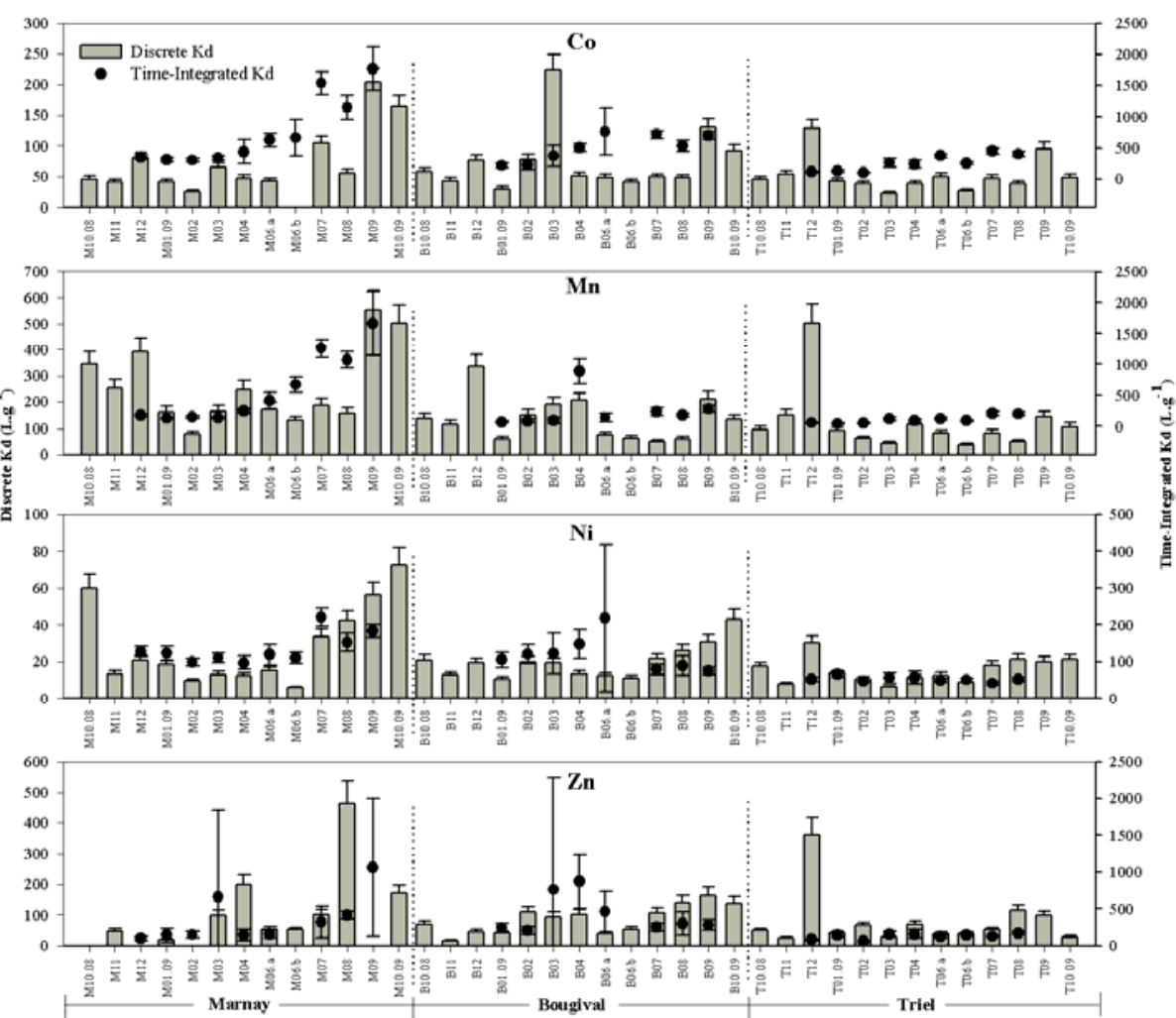

Figure 3. "Discrete" CI (concentration ratio of metals in SPM $(>0.45 \mu \mathrm{m})$ to dissolved metals $(<0.45 \mu \mathrm{m})$ both collected by discrete sampling) $(\mathrm{L} / \mathrm{g})$ are presented as bars, indicating "discrete" CI from Marnay, Bougival and Triel from left to right from October 2008 to October 2009. "Time - Integrated" CI (concentration ratio of metals in SPM collected in sediment trap to labile metals measured by DGT) (L/g) are presented as dotted line indicating "time-integrated” CI from Marnay, Bougival and Triel for each month during sampling from December 2008 - September 2009 (Indicated month corresponding to collection time with deployment time the month before) 
Individual CI values were also compared in order to identify temporal variation during the one-year campaign (Fig. 3). In general, temporal variations were higher at Marnay than at Bougival and Triel, except for a few extreme events where CI values increased dramatically at the two downstream sites. Indeed, there was a high variation of discrete CI values for five elements, $\mathrm{Co}, \mathrm{Cu}, \mathrm{Mn}, \mathrm{Ni}$ and $\mathrm{Zn}$ at Marnay that was significantly less visible at Triel: at Marnay, relative standard deviations for discrete CI were $69 \%, 84 \%$ and $73 \%$ for $\mathrm{Co}, \mathrm{Cu}$ and $\mathrm{Ni}$, respectively, whereas at Triel, RSD for discrete CI were $54 \%$, $44 \%$ and $51 \%$ for $\mathrm{Co}, \mathrm{Cu}$ and $\mathrm{Ni}$, respectively. These higher variations of discrete $\mathrm{CI}$ values at Marnay compared to Triel were also observed for time-integrated CI for $\mathrm{Cu}$ and Ni. RSD for time-integrated CI at Marnay were $102 \%$ and $29 \%$ for $\mathrm{Co}$ and $\mathrm{Ni}$, respectively, and at Triel, RSD for time-integrated CI at Triel were 51\% and $12 \%$ for Co and Ni, respectively. In addition to Co, $\mathrm{Cu}$ and $\mathrm{Ni}, \mathrm{Mn}$ and $\mathrm{Zn}$ average values of time-integrated $\mathrm{CI}$ decreased at Triel compared to those at Marnay. This evolution was not observed on average values of discrete $\mathrm{CI}$ for $\mathrm{Mn}$ and $\mathrm{Zn}$. $\mathrm{Cr}$, Cd and $\mathrm{Pb}$ were not compared because most of their discrete $\mathrm{CI}$ at Marnay was lower than QL.

Observing the different trends on temporal variation of CI, it was possible to divide the metals into two groups. The first group consisted of Co, Mn, Ni, and Zn with a significantly higher discrete and time-integrated CI at Marnay than at Triel notably for the summer months from July to October. The second group included $\mathrm{Cd}, \mathrm{Cr}, \mathrm{Cu}$ and $\mathrm{Pb}$. Due to discrete $\mathrm{CI}$ at Marnay being below quantification limits for these metals, observations are made on time-integrated CI. These metals have relatively comparable CI values between Marnay and Triel both in low and high flows, with higher CI at Bougival during certain periods. The only period where Cd displayed a discrete CI at Marnay higher than at Triel was in the month of October 2008. The discrete CI of $\mathrm{Cr}$ multiplied up to six to ten fold in one site between two different periods. Values increased from $27 \pm 3.9,70 \pm$ 9.9, and $47 \pm 6.7$ at Marnay, Bougival and Triel, respectively, and $272 \pm 38.8$ on April 2009, an increase of 11, 5 and 6 times at Marnay, Bougival and Triel, respectively.

\section{Discussion}

\subsection{Discrete vs. time-integrated concentration indexes}

The comparison between discrete and time-integrated metal concentration index (CI) originated from the need for an environmental indicator representative of the medium- and long-term trend in the milieu. As the frequency of discrete sampling for metal monitoring is often limited by labor factors, this study was aimed at considering time-integrated metal concentration index as an option. Difficulties faced in measuring $\mathrm{CI}$ for $\mathrm{Cd}, \mathrm{Pb}$ and $\mathrm{Cr}$ due to low dissolved concentrations were overcome by using DGT that concentrates labile metals over a period of time. Passive and time-integrated samplers also hold great potential in the cross-validation of biological accumulation under field conditions ${ }^{6,34}$. The source of the high variability in time integrative CI was DGT measurements, their uncertainty levels are higher than metal concentrations in sediment traps.

The authors are aware that the two CI values do not represent the same partitioning, mostly because dissolved metals do not coincide with labile metals. Some inert dissolved metal complexes are not sampled by DGT. Consequently, timeintegrated CI calculated using labile metals measured by DGT would result in higher CI values than discrete CI, and the difference is amplified for metals with a low lability in water. This would be the reason why $\mathrm{Cu}$, $\mathrm{Zn}$ and $\mathrm{Co}$ were ranked differently between discrete and time-integrated CI.

In order to further investigate whether time-integrated CI could be representative as an environmental indicator, partitioning evolution between sites over a year was investigated. Statistical tests performed previously in section 3.3 showed that time-integrated metal partitioning is more effective in differentiating spatial evolution. As physico-chemical parameters between the three sites are significantly different, metal partitioning at the three sites are also expected to vary. Differences in CI values between Marnay and Triel were not significant when evaluated with discrete values whereas it was considered different when comparing time-integrated values. Regarding temporal variation, Co, Mn and Ni had significantly higher discrete and timeintegrated CI at Marnay than at Triel notably for the summer months from July to October. On the other hand, Cr and Cu showed relatively stable discrete and time-integrated CI values between Marnay and Triel both in low and high flows, with possible higher CI at Bougival during certain periods. This similarity of temporal variation between discrete and time-integrated CI means that to a certain extent, one month time-integrated CI is capable of illustrating temporal variation of metal partitioning in the water column.

The biggest challenge in performing environmental monitoring is the representativeness of samples in respect with spatial and temporal evolution. Collected samples are expected to represent the water column without being over or undermagnified by extreme events or sudden variations. Although discrete CI captures instant variations that may be significantly different, variations are irregular depending on sampling period and thus a general trend is hardly observable. The differences observed when comparing discrete and time-integrated CI in this study suggest that although time-averaged CI gives averaged 
and consequently "buffered" values, it averages short-term variation and enhances sustainable and medium- to long-term variation in a given site.

\subsection{Urbanization impacts observed by time-integrated CI}

Recent studies showed that metal speciation in the solid phase ${ }^{35}$ and metal accumulation in aquatic species ${ }^{34}$ were $^{2}$ modified downstream of the urbanized Greater Paris Region. With this study, change in land use not only affects metal speciation but also partitioning between the solid and the dissolved phase of urban-enriched metals. Previously discussed results demonstrated the difference in temporal variation between upstream and downstream (smaller standard variation for the upstream Marnay data set compared to the Triel data set for $\mathrm{Co}, \mathrm{Cu}$ and $\mathrm{Ni}$ ) and higher discrete and time-integrated CI at Marnay from July to October for Co, Mn, Ni, and Zn. Urbanization was likely to affect metal partitioning in the Seine River. This impact is evidenced by time-integrated CI differences between upstream and downstream of the Greater Paris Region observed for enriched metals above. On the other hand, such differences were not observed for $\mathrm{Cr}$, a non-enriched metal in the Seine River despite the physico-chemical evolution on a given period from Marnay to Triel.

The behavior of metals enriched by anthropogenic activities downstream seems to be controlled by different parameters compare to metal behavior at the upstream site. This is seen both through statistical differences between CI at Marnay and Triel and the higher fluctuating CI at Marnay compared to Triel. Spearman correlation tests (significance level p < 0.05) were performed separately between Marnay representing the non-urban site, and Bougival and Triel, representing the anthropogenic sites, to further investigate key factors affecting metal behavior in the water column. No significant direct correlation between CI and the measured physico-chemical parameters was found. This is due to differences in governing processes and response level between metal concentrations in the solid and the dissolved fraction. While no significant correlation was found either between solid metals and physico-chemical parameters, dissolved metals appeared to be correlated to some water parameters. Higher temporal variation in Marnay compared to Triel is likely due to the dissolved metal concentration at Marnay being more correlated with flow-related parameters which can fluctuate significantly. Upstream, correlations of some dissolved metals with conductivity were relatively high $\left(\mathrm{Cu} \mathrm{r}^{2}=0.657 ; \mathrm{Mn} \mathrm{r}^{2}=0.699\right.$; $\left.\mathrm{Ni} \mathrm{r}^{2}=0.804\right)$ while being negatively correlated with discharge (Cu $\mathrm{r}^{2}=-0.736$; $\left.\mathrm{Mn} \mathrm{r}^{2}=-0.813 ; \mathrm{Zn} \mathrm{r}^{2}=-0.688\right)$. Downstream, dissolved metal concentrations were less correlated with fluctuating flowrelated parameters and were more correlated with redox-related parameters such as DOC (Co r ${ }^{2}=0.655$; Cu r ${ }^{2}=0.469$; Mn $r^{2}=$ 0.507; $\left.\mathrm{Ni} \mathrm{r}^{2}=0.574\right)$ and temperature ( $\left.\mathrm{Cd} \mathrm{r}^{2}=0.531 ; \mathrm{Cu} \mathrm{r}^{2}=0.523 ; \mathrm{Mn} \mathrm{r}^{2}=0.602 ; \mathrm{Pb} \mathrm{r}^{2}=0.724\right)$ while displaying negative correlation with $\mathrm{pH}\left(\mathrm{Cd} \mathrm{r}^{2}=-0.608\right.$; $\mathrm{Co}^{2}=-0.552$; $\left.\mathrm{Cu} \mathrm{r}^{2}=-0.805 ; \mathrm{Mn} \mathrm{r}^{2}=-0.697 ; \mathrm{Pb} \mathrm{r}^{2}=-0.501\right)$. Higher temporal fluctuations of CI at Marnay compared to Triel may be explained by the correlation of metal concentrations with these different water parameters. As discharge varies considerably compared to DOC, temperature and $\mathrm{pH}$, metal concentrations at Marnay would also vary to a higher extent than at Bougival and Triel. Downstream, dissolved metal concentrations seemed more affected by sorption processes. Their concentrations are more correlated with DOC, temperature and $\mathrm{pH}$ than at Marnay. These three parameters are known to control adsorption and desorption reactions on surfaces. Temperature and $\mathrm{pH}$ are known to control point zero charge (PZC) of adsorption on many mineral surfaces ${ }^{36,37}$ and DOC is known to form complexes with available dissolved metals ${ }^{38}$. Adsorption to the solid phase maybe an important process controlling fluctuation of metal partitioning and mobility in the water column downstream.

\section{Conclusion}

Comparison of discrete and time-integrated metal partitioning in the water column of the Seine River demonstrated the capability of time-integrated concentration index (CI) to represent spatial and temporal variation of metal variation trend. Although it is recognized that time-integrated CI does not measure the exact same pool as discrete CI, time-integrated CI could be useful to study medium- and longterm trends of metal partitioning in river systems related to urbanization, reducing the labor costs needed to obtain representative discrete metal sampling. It could also be related to bioaccumulation, which is also a timeintegrated phenomenon. $\mu$ Further investigation of time-integrated CI should be performed on other watersheds to study the effectiveness of this method on other water systems.

\section{Acknowledgements}

The authors would like to thank Aurelie Germain, Cécile Mirande- Bret, Emmanuelle Uher and Stéphanie Pacini for sampling and analytical assistance; Eric Robin for XRF analytical assistance; Eric Douville and Louise Bordier for assistance in ICP-MS measurements; Caroline Gauthier and Christine Hatté for particulate carbon analysis; the Marnay botanical garden and SIAAP for giving access to sampling sites; Vincent Rocher and the SIAAP team and William Thomas and the SNS team for data. 
This project was financially supported by INSU (EC2CO) for the MEDISIS project and the French research program PIREN Seine. Cindy Priadi recognizes the French foreign affairs ministry and CNRS and Adeline Bourgeault recognizes the Ile de France Region for scholarship. This is LSCE contribution number 4407.

\section{References}

1. S. N. Luoma and P. S. Rainbow, Metal Contamination in Aquatic Environments, Cambridge University Press, Cambridge, 2008.

2. M. F. Hochella and A. F. White, Rev. Miner., 1990, 23, 1-16.

3. W. Stumm and J. J. Morgan, Aquatic Chemistry, 2 edn., Wiley-Interscience, Toronto, 1981.

4. S. Lofts and E. Tipping, The Science of The Total Environment, 2000, 251-252, 381-399.

5. E. R. Unsworth, K. W. Warnken, H. Zhang, W. Davison, F. Black, J. Buffle, J. Cao, R. Cleven, J. Galceran, P. Gunkel, E. Kalis, D. Kistler, H. P. Van Leeuwen, M. Martin, S. Noel, Y. Nur, N. Odzak, J. Puy, W. Van Riemsdijk, L. Sigg, E. Temminghoff, M. L. Tercier-Waeber, S. Toepperwien, R. M. Town, L. P. Weng and H. B. Xue, Environmental Science \& Technology, 2006, 40, 1942-1949.

6. D. A. L. Vignati, S. Valsecchi, S. Polesello, L. Patrolecco and J. Dominik, TrAC Trends in Analytical Chemistry, 2009, 28, 159-169.

7. Y. Lu and H. E. Allen, The Science of The Total Environment, 2001, 277, 119-132.

8. R. L. Bibby and J. G. Webster-Brown, Science of The Total Environment, 2005, 343, 177-197.

9. H. L. Nguyen, M. Leermakers, M. Elskens, F. De Ridder, T. H. Doan and W. Baeyens, Science of The Total Environment, 2005, 341, 211-226. H. P. Jarvie, C. Neal, D. V. Leach, G. P. Ryland, W. A. House and A. J. Robson, Science of The Total Environment, 1997, 194, 285-302.

10. D. J. O'Connor and J. P. Connolly, Water Research, 1980, 14, 1517-1523. M. M. Shafer, S. R. Hoffmann, J. T. Overdier and D. E. Armstrong, Environmental Science \& Technology, 2004, 38, 3810-3819.

11. A. A. Koelmans and H. Radovanovic, Water Science and Technology, 1998 37, 71-78.

12. B. Ng, A. Turner, A. O. Tyler, R. A. Falconer and G. E. Millward, Water Research, 1996, 30, 63-74.

13. R. J. K. Dunn, P. R. Teasdale, J. Warnken and J. M. Arthur, Environmental Pollution, 2007, 148, $213-220$.

14. L. Tessier, PhD Thesis, Ecole Nationale des Ponts et Chaussées, 2003.

15. J. Gasperi, S. Garnaud, V. Rocher and R. Moilleron, Science of The Total Environment, 2008, 407, 263-272.

16. P. Ciffroy, D. Vazelle, V. Mataix, J. Taconnet, A. Estèbe, D. Thévenot, O. Bourguignon, Z. ldlafkih and M. Meybeck, Hydroécol. Appl. , 1999, 11, 71-102.

17. W. Davison and H. Zhang, Nature, 1994, 367, 546-548.

18. M. H. Tusseau-Vuillemin, R. Gilbin, E. Bakkaus and J. Garric, Environmental Toxicology and Chemistry, 2004, 23, 2154-2161.

19. R. Buzier, M.-H. Tusseau-Vuillemin and J.-M. Mouchel, Science of The Total Environment, 2006, 358, 277-285.

20. D. R. Thévenot, R. Moilleron, L. Lestel, M.-C. Gromaire, V. Rocher, P. Cambier, P. Bonté, J.-L. Colin, C. de Pontevès and M. Meybeck, Science of The Total Environment, 2007, 375, 180-203.

21. M. Meybeck, L. Lestel, P. Bonte, R. Moilleron, J. L. Colin, O. Rousselot, D. Herve, C. de Ponteves, C. Grosbois and D. R. Thevenot, Science of The Total Environment, 2007, 375, 204-231.

22. M. H. Tusseau-Vuillemin, C. Gourlay, C. Lorgeoux, J. M. Mouchel, R. Buzier, R. Gilbin, J. L. Seidel and F. ElbazPoulichet, Science of The Total Environment, 2007, 375, 244-256.

23. SIAAP, Dossier du maitre d'ouvrage, http://www.debatpublic-station554epuration-seineaval.org/docs/pdf/dossiermo/doc-synthese-2.pdf, Accessed 6 May 2010.

24. G. Billen, M. Silvestre, S. Barles, J. M. Mouchel, J. Garnier, F. Curie and P. Boët, in Eau Seine Normandie, ed. PirenSeine, Paris, Editon edn., 2009, vol. 7.

25. M. H. Tusseau-Vuillemin, J. Dispan, J. M. Mouchel and P. Servais, Water Research, 2003, 37, $2242-2247$.

26. S. J. Traina, J. Novak and N. E. Smeck, Journal of Environmental Quality, 1990, 19, 151-153.

27. A. Bourgeault, C. Gourlay-Francé, F. Vincent-Hubert, F. Palais, A. Geffard, S.Biagianti-Risbourg, S. Pain-Devin and M. H. Tusseau-Vuillemin, Environmental Toxicology, 2010, 25, 468-478.

28. A. Bourgeault, C. Gourlay-Francé and M. H. Tusseau-Vuillemin, 2010, 29, 2182-2189.

29. M. F. Le Cloarec, P. H. Bonte, L. Lestel, I. Lefèvre and S. Ayrault, Physics and Chemistry of the Earth, Parts A/B/C, In Press, In Press.

30. S. Ayrault, C. R. Priadi, O. Evrard, I. Lefevre and P. Bonte, Journal of Environmental Monitoring, 2010, 12, 21772185. 
31. F. Elbaz-Poulichet, J.-L. Seidel, C. Casiot and M.-H. Tusseau-Vuillemin, Science of The Total Environment, 2006, 367, 278-287.

32. D. Thévenot, L. Lestel, M.-H. Tusseau-Vuillemin, J. L. Gonzalez and M. Meybeck, in Eau Seine Normandie, ed. PirenSeine, Paris, Editon edn., 2009, vol. 7.

33. J.-F. Chiffoleau, D. Cossa, D. Auger and I. Truquet, Marine Chemistry, 1994, 578 47, 145-158.

34. A. Bourgeault, C. Gourlay-Francé, C. Priadi, S. Ayrault and M.-H. Tusseau-Vuillemin, Aquatic Toxicology, submitted.

35. C. Priadi, S. Ayrault, S. Pacini, P. Bonte. International Journal of Environmental Science and Technology. 2011. 8, 118.

36. D.-m. Dong, X.-m. Zhao, X.-y. Hua, J.-j. Zhang and S.-m. Wu, Chem. Res. Chin. Univ., 2007, 23, 659-664.

37. Y. Li, X. L. Wang, G. H. Huang, B. Y. Zhang and S. H. Guo, Soil and Sediment Contamination: An International Journal, 2009, 18, 87 - 101.

38. B. Pernet-Coudrier, L. Clouzot, G. Varrault, M. H. Tusseau-Vuillemin, A.Verger and J. M. Mouchel, Chemosphere, 2008, 73, 593-599.

\section{Environmental impact}

Using metal concentration data from the water column, discrete concentration index, calculated from the ratio between discrete solid metal concentration and discrete dissolved metal concentration, was compared with time-integrated concentration index, calculated as a ratio between solid metal concentration from sediment traps and labile metals measured by DGT. The comparison of the two data sets demonstrated the capability of time-integrated concentration index to represent spatio-temporal trends in metal variation trends. Time-integrated concentration index is useful to study medium and long-term trends of metal partitioning in river systems related to urbanization, reducing the labor costs needed to obtain representative discrete metal sampling. It could also be related to bioaccumulation, which is also a time-integrated phenomenon. This study will contribute to enriching the existing methods of environmental monitoring in aquatic systems so that water agencies and stakeholders may have a monitoring option which suits their budget and human resource constraints. 


\section{Supporting Information 1 : Sediment digestion protocol}

SPM was digested completely during 3-4 weeks using various acids at different temperatures. The complete discrete SPM samples+filter (MF-Millipore cellulose ester filters) and $0.1 \mathrm{~g}$ of time-integrated SPM from sediment trap were digested in Teflon vessels under laminar flow hood using a heating block (Digiprep, SCP Science) using 3 solutions:

1. The first attack uses $15 \mathrm{~mL}$ aqua regia $\left(\mathrm{HNO}_{3} 65 \%\right.$ : $\left.\mathrm{HCl} 30 \%, 3: 1\right)$ for 3 days at room temperature (vessel capped). Excess nitrogen dioxide was then evaporated at $90^{\circ} \mathrm{C}$ for 2 hours. This step assured the dissolution of $\mathrm{Ca}$ and $\mathrm{Mg}$, abundant in the Seine River. Remaining liquid in vessels were pipetted (VWR, low density polyethylene) into a disposable tube (Falcon, polypropylene) and carefully avoiding pipetting the sediment. The remaining sediment was rinsed with $10 \mathrm{~mL} 0.5 \mathrm{~N} \mathrm{HNO}_{3}$ This was performed 3 times to ensure the evacuation of $\mathrm{Ca}$ and $\mathrm{Mg}$, previously dissolved by aqua regia, and avoid re-precipitation of $\mathrm{Ca}$ and $\mathrm{Mg}$ fluorides in $\mathrm{HF}$ solution.

2. Digestion continued with $10 \mathrm{~mL}$ of a $\mathrm{HF}(48.9 \%): \mathrm{HNO}_{3}(65 \%)$ mixture (1:1) to attack siliceous minerals during $24 \mathrm{~h}$ at room temperature (vessels capped). Sample was then evaporated to near dryness at $100^{\circ} \mathrm{C}$ to eliminate hexafluorosilicic acid (3-5 days).

3. The solid residue was then attacked with $12 \mathrm{~mL}$ of a $\mathrm{HNO}_{3} 65 \%: \mathrm{HClO}_{4} 69-72 \%$ (1:1) mixture heated at $120^{\circ} \mathrm{C}$ during 5 days (vessels capped). This step is aimed to oxidize organic matter. Final solutions were again evaporated to near dryness to eliminate perchloric acid. Pipetted solution recovered in separate tubes during the first step using aqua regia were re-introduced to the Teflon vessels and were again evaporated near to dryness. Afterwards, $1 \mathrm{~mL} 618$ of $65 \% \mathrm{HNO}_{3}$ was added to the remaining solution and evaporated to near dryness. This step was repeated three 
times to ensure minimal residue of chloride ions. The solutions were then brought into a $50 \mathrm{~mL} 0.5 \mathrm{~N} \mathrm{HNO}_{3}$ solution for ICP-MS analysis. This method was adopted for total SPM digestion of the highly carbonated SPM of Seine River. All solutions were made from ultrapure reagents to minimize contamination $\left(\mathrm{HNO}_{3}\right.$ and $\mathrm{HCl}$ Normatom grade, VWR France, and $\mathrm{HF}$ and $\mathrm{HClO}_{4}$ "for trace metal analyses", Baker, from Sodipro France). For each digestion, $0.1 \mathrm{~g}$ of a certified lake sediment reference material was also digested (SL1, International Atomic Energy Agency IAEA). 
S2 : concentration of various parameters during sampling campaign

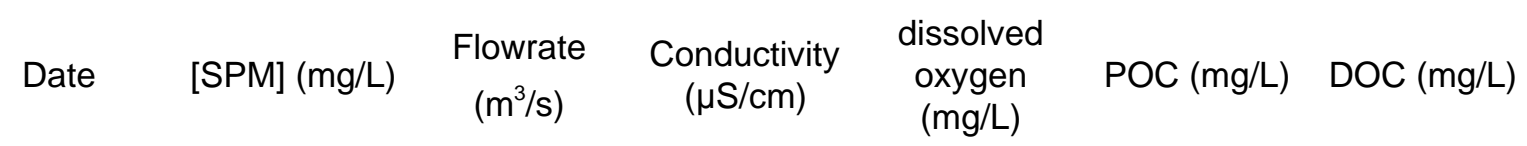

\section{Marnay}

22.10.08

25.11 .08

16.12 .08

19.01 .09

24.02 .09

24.03 .09

22.04 .09

09.06 .09

22.06.09

22.07.09

19.08 .09

24.09.09

22.10 .09

\section{Bougival}

22.10.08

25.11.08

16.12 .08

19.01 .09

24.02.09

24.03.09

22.04.09

09.06 .09

22.06.09

22.07.09

19.08 .09

24.09.09

22.10 .09

Triel

22.10.08

25.11.08

16.12 .08

19.01 .09

24.02.09

24.03.09

22.04.09

09.06 .09

22.06.09

22.07.09

19.08.09

24.09.09

22.10.09

$\mathrm{nm}=$ non

measured

$<Q L=$ lower than

quantification limit
$4,0 \quad 59$

9,5

33,4

20,2

19,4

10,8

20,4

7,0

5,9

11,4

4,4

5,7

4,7

10,9

11,1

44,1

21,2

15,7

9,3

7,7

16,8

6,4

10,9

7,9

9,7

8,5

187

221

295

215

324

212

184

167

116

148

97

92

112

7,8

334

391

495

383

550

384

340

375

228

209

211

198

225

8,8
4,8
395

474

495

485

$\mathrm{nm}$

509

516

490

526

402

364

268

350

446

490

501

557

$\mathrm{nm}$

570

611

606

609

550

527

474

498

538

506

513

612

$\mathrm{nm}$

619

655

668

668

655

604

619

625 $\mathrm{nm}$

$\mathrm{nm}$

$\mathrm{nm}$

$\mathrm{nm}$

$\mathrm{nm}$

$\mathrm{nm}$

$\mathrm{nm}$

$\mathrm{nm}$

$\mathrm{nm}$

$\mathrm{nm}$

$\mathrm{nm}$

$\mathrm{nm}$

$\mathrm{nm}$

9,5

10,5

12,2

12,8

11,8

11,3

8,9

6,3

5,1

6,8

6,8

7,4

8,0

7,5

9,1

12,5

12,1

12,7

10,0

8,0

6,0

6,0

5,8

6,1

5,9

6,1
0,42

0,61

1,90

1,20

0,88

0,56

0,90

0,45

0,05

0,42

0,29

1,23

0,34

2,68

1,83

1,94

1,62

1,95

1,75

2,57

2,16

2,05

2,23

1,73

2,44

2,38

2,94

2,79

3,51

2,77

2,77

2,69

3,00

4,34

3,21

3,25

3,73

2,56

2,64

0,69

0,04

4,16

3,87

4,14

3,97

3,42

3,72

3,77

5,45

3,63

3,96

3,54

3,84

3,93 


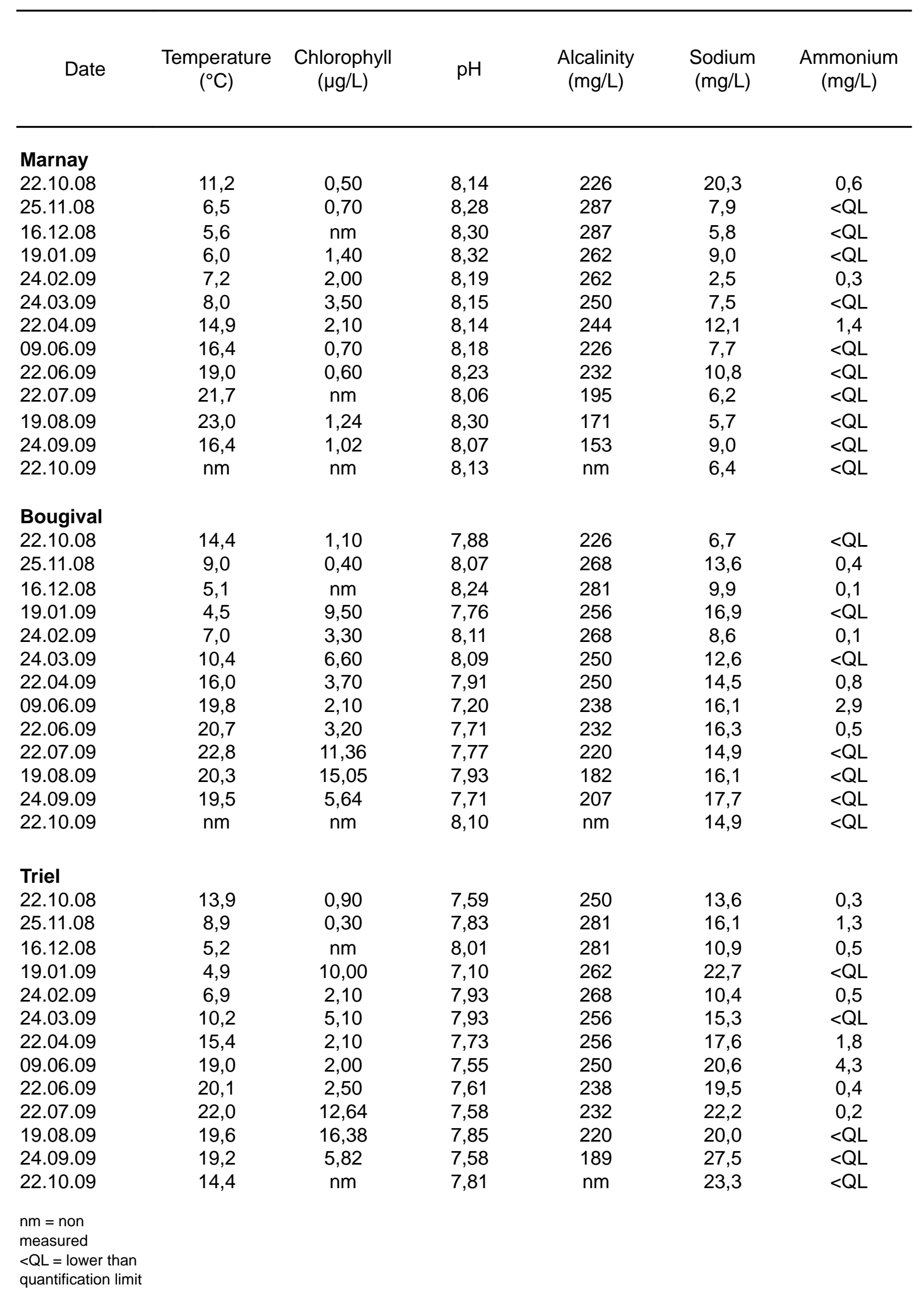




\begin{tabular}{|c|c|c|c|c|c|c|}
\hline Date & $\begin{array}{l}\text { Potassium } \\
\text { (mg/L) }\end{array}$ & $\begin{array}{l}\text { Magnesium } \\
(\mathrm{mg} / \mathrm{L})\end{array}$ & $\begin{array}{l}\text { Calcium } \\
(\mathrm{mg} / \mathrm{L})\end{array}$ & $\begin{array}{l}\text { Chloride } \\
(\mathrm{mg} / \mathrm{L})\end{array}$ & Nitrite (mg/L) & Nitrate $(\mathrm{mg} / \mathrm{L})$ \\
\hline \multicolumn{7}{|l|}{ Marnay } \\
\hline 22.10 .08 & 6,3 & 6,8 & 88,3 & 13,9 & $<Q L$ & 14,8 \\
\hline 25.11.08 & $<Q L$ & 4,7 & 98,4 & 14,3 & $<Q L$ & 20,4 \\
\hline 16.12 .08 & $<Q L$ & 3,3 & 105 & 12,7 & $<Q L$ & 24,8 \\
\hline 19.01.09 & 1,9 & 3,9 & 93,2 & 18,6 & $<Q$ & 26,0 \\
\hline 24.02 .09 & $<Q L$ & 0,5 & 88,1 & 15,1 & $<\mathrm{QL}$ & 24,9 \\
\hline 24.03 .09 & 1,6 & 4,0 & 88,9 & 19,6 & $<Q L$ & 25,7 \\
\hline 22.04 .09 & 6,0 & 4,3 & 93,2 & 27,2 & $<Q L$ & 25,9 \\
\hline 09.06 .09 & 2,1 & 3,6 & 89,2 & 21,1 & $<Q L$ & 16,1 \\
\hline 22.06 .09 & 2,4 & 4,0 & 87,8 & 23,3 & $<Q L$ & 18,0 \\
\hline 22.07.09 & 2,0 & 7,6 & 72,4 & 12,9 & $<Q L$ & 11,3 \\
\hline 19.08.09 & 1,9 & 8,9 & 64,8 & 12,0 & $<Q L$ & 8,8 \\
\hline 24.09 .09 & $<Q L$ & 1,3 & 58,0 & 11,4 & $<Q L$ & 7,8 \\
\hline 22.10 .09 & $<Q L$ & 1,4 & 59,6 & 12,7 & $<Q L$ & 7,8 \\
\hline \multicolumn{7}{|l|}{ Bougival } \\
\hline 22.10 .08 & 2,2 & 3,4 & 77,3 & 23,9 & $<Q L$ & 19,2 \\
\hline 25.11.08 & $<Q L$ & 6,7 & 94,7 & 19,1 & $<Q$ & 19,2 \\
\hline 16.12 .08 & $<Q L$ & 0,6 & 99,6 & 17,4 & $<Q L$ & 25,0 \\
\hline 19.01.09 & 3,4 & 6,4 & 100 & 30,1 & $<Q L$ & 26,1 \\
\hline 24.02 .09 & 2,8 & 6,2 & 97,7 & 22,7 & $<Q L$ & 25,5 \\
\hline 24.03 .09 & 2,9 & 6,4 & 96,8 & 26,2 & $<Q L$ & 26,7 \\
\hline 22.04 .09 & 3,4 & 7,8 & 97,6 & 30,7 & $<Q$ & 24,1 \\
\hline 09.06.09 & 4,6 & 6,7 & 95,5 & 34,2 & $<Q ⿱ \mathrm{QL}$ & 24,4 \\
\hline 22.06 .09 & 4,4 & 7,1 & 91,4 & 32,3 & $<Q$ & 21,3 \\
\hline 22.07 .09 & 4,3 & 10,3 & 85,0 & 29,2 & $<Q L$ & 15,1 \\
\hline 19.08.09 & 4,0 & 7,0 & 79,8 & 29,0 & $<Q L$ & 14,5 \\
\hline 24.09 .09 & 0,4 & 3,2 & 72,9 & 25,5 & $<Q L$ & 13,2 \\
\hline 22.10 .09 & 0,7 & 3,3 & 74,1 & 26,6 & $<Q L$ & 13,9 \\
\hline \multicolumn{7}{|l|}{ Triel } \\
\hline 22.10 .08 & 3,9 & 5,4 & 77,5 & 34,7 & 1,2 & 27,9 \\
\hline 25.11.08 & $<Q L$ & 7,9 & 98,7 & $<Q L$ & 26,4 & 20,2 \\
\hline 16.12 .08 & $<Q L$ & 0,7 & 98,6 & 19,9 & $<Q L$ & 28,5 \\
\hline 19.01.09 & 4,3 & 7,3 & 102 & 41,3 & 0,8 & 28,2 \\
\hline 24.02 .09 & 3,2 & 7,0 & 109 & 25,7 & 0,8 & 28,3 \\
\hline 24.03 .09 & 3,7 & 7,3 & 102 & 31,9 & $<Q L$ & 35,2 \\
\hline 22.04 .09 & 4,0 & 8,1 & 102 & 35,5 & 0,9 & 31,9 \\
\hline 09.06.09 & 5,7 & 7,9 & 101 & 41,9 & $<Q L$ & 33,7 \\
\hline 22.06 .09 & 5,3 & 8,6 & 95,5 & 38,3 & $<Q L$ & 29,5 \\
\hline 22.07 .09 & 6,0 & 8,6 & 94,1 & 41,1 & $<Q L$ & 31,3 \\
\hline 19.08.09 & 5,4 & 8,6 & 89,1 & 35,6 & $<Q L$ & 22,1 \\
\hline 24.09 .09 & 1,5 & 5,8 & 84,6 & 40,3 & 2,2 & 28,7 \\
\hline 22.10 .09 & 9,2 & 5,5 & 86,3 & 41,6 & 3,2 & 25,3 \\
\hline \multicolumn{7}{|l|}{$\mathrm{nm}=\mathrm{non}$} \\
\hline measured & & & & & & \\
\hline $\begin{array}{l}<\mathrm{QQ}=\text { lower th } \\
\text { quantification }\end{array}$ & & & & & & \\
\hline
\end{tabular}




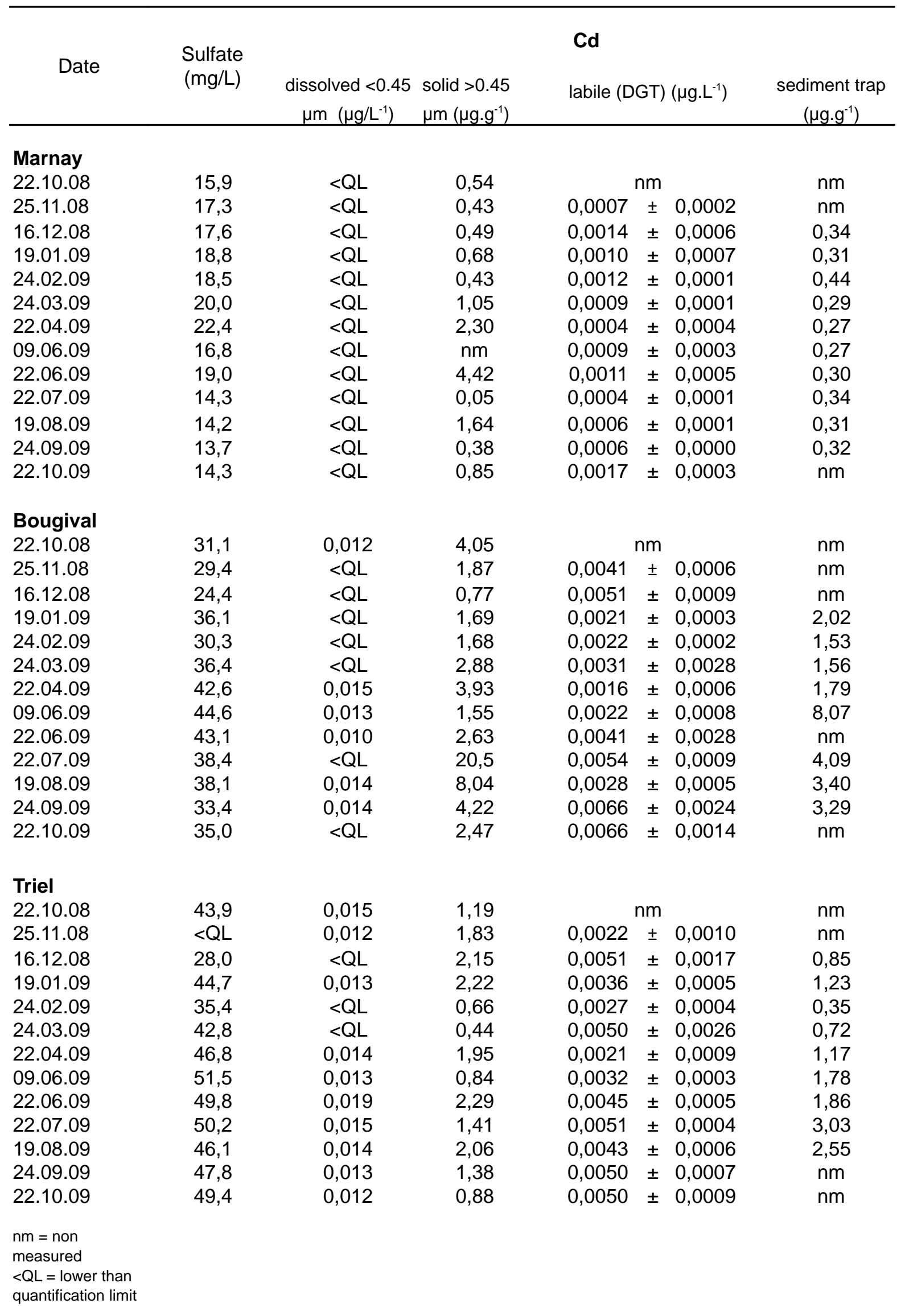




\section{$\mathrm{Cr}$}

\begin{tabular}{cclcc} 
Date & $\begin{array}{c}\text { dissolved } \\
<0.45 \mu \mathrm{m}\end{array}$ & solid $>0.45 \mu \mathrm{m}$ & labile (DGT) $\left(\mu \mathrm{g} \cdot \mathrm{L}^{-1}\right)$ & $\begin{array}{c}\text { sediment trap } \\
\left(\mu \mathrm{g} \cdot \mathrm{g}^{-1}\right)\end{array}$ \\
\hline & $\left(\mu \mathrm{g} / \mathrm{L}^{-1}\right)$ & $\left(\mu \mathrm{g} \cdot \mathrm{g}^{-1}\right)$ &
\end{tabular}

Marnay

22.10.08

25.11.08

$<$ QL $\quad 7,7$

16.12 .08

19.01 .09

24.02.09

24.03.09

22.04.09

09.06 .09

22.06.09

22.07.09

19.08 .09

24.09.09

22.10.09

1,09

30,0

nm $0,0184 \pm 0,0025$

$\mathrm{nm}$

$<Q L \quad 68,7$

$0,0180 \pm 0,0021$

$\mathrm{nm}$

$<Q L$

41,9

$0,0352 \pm 0,0062$

53,7

$<$ Q

14,9

$0,0250 \pm 0,0020$

50,1

$<$ QL $\quad 57,2$

$0,0249 \pm 0,0038$

42,1

0,22

64,8

$<Q L \quad 50,2$

$<$ Q

$<$ Q

64,8

$0,0333 \pm 0,0110$

50,0

$0,0214 \pm 0,0033$

50,8

$<\mathrm{QL} \pm 0,0000$

49,9

$0,0178 \pm 0,0027$

50,2

46,0

$0,0196 \pm 0,0026$

51,2

0,41

53,6

65,3

$<\mathrm{QL}$

$0,0167 \pm 0,0041$

51,4

$0,0196 \pm 0,0078$

54,2

$\mathrm{nm}$

\section{Bougival}

22.10.08

25.11.08

0,54

88,9

1,04

73,0

16.12 .08

$<\mathrm{QL}$

$<$ Q

65,2

19.01.09

24.02.09

24.03.09

$<\mathrm{QL}$

46,3

0,60

84,2

102

22.04.09

90,6

09.06 .09

0,28

75,5

22.06.09

$<\mathrm{QL}$

0,25

77,5

$<$ QL $\quad 82,0$

19.08 .09

0,51

102

24.09.09

$<Q L$

84,7

22.10.09

$<Q L$

85,4

\begin{tabular}{lll}
\multicolumn{3}{c}{$\mathrm{nm}$} \\
0,0574 & $\pm 0,0248$ \\
0,0926 & \pm & 0,0131 \\
0,0270 & \pm & 0,0060 \\
0,0583 & \pm & 0,0304 \\
0,0353 & \pm & 0,0033 \\
0,0291 & \pm & 0,0081 \\
0,0244 & \pm & 0,0065 \\
0,0024 & \pm & 0,0035 \\
0,0323 & \pm & 0,0054 \\
0,0277 & \pm & 0,0033 \\
0,0211 & \pm & 0,0024 \\
0,0246 & \pm & 0,0108
\end{tabular}

$\mathrm{nm}$

$\mathrm{nm}$

$\mathrm{nm}$

71,8

83,0

69,2

70,0

109

$\mathrm{nm}$

109

87,8

92,2

$\mathrm{nm}$

Triel

22.10.08

$<\mathrm{QL}$

94,9

$\mathrm{nm}$

$\mathrm{nm}$

25.11.08

1,24

58,1

$0,0314 \pm 0,0112$

$\mathrm{nm}$

16.12 .08

122

19.01 .09

65,6

$0,0857 \pm 0,0081$

61,0

0,23

$0,0284 \pm 0,0035$

73,5

$<\mathrm{QL}$

46,6

24.03.09

35,9

0,32

$0,0452 \pm 0,0111$

56,4

22.04.09

88,3

09.06 .09

69,1

65,0

$<\mathrm{QL}$

$0,0372 \pm 0,0101$

71,7

$0,0243 \pm 0,0031$

80,9

0,21

58,1

22.07 .09

88,1

$0,0083 \pm 0,0069$

78,3

0,21

74,2

24.09.09

$<\mathrm{QL}$

77,3

$0,0314 \pm 0,0047$

86,0

$0,0256 \pm 0,0026$

86,7

$0,0319 \pm 0,0165$

$\mathrm{nm}$

0,32

60,5

$0,0252 \pm 0,0039$

$\mathrm{nm}$

$\mathrm{nm}=$ non

measured

$<\mathrm{QL}=$ lower than

quantification limit 


\section{Co}

Date

dissolved $<0.45 \mu \mathrm{m}$ solid $>0.45 \mu \mathrm{m}$

labile (DGT) $\left(\mu \mathrm{g} \cdot \mathrm{L}^{-1}\right)$

sediment trap

$\left(\mu \mathrm{g} / \mathrm{L}^{-1}\right)$

$\left(\mu \mathrm{g} . \mathrm{g}^{-1}\right)$

$\left(\mu \mathrm{g} \cdot \mathrm{g}^{-1}\right)$

Marnay

22.10.08

25.11.08

0,16

7,39

0,18

7,61

16.12 .08

0,11

8,62

0,16

6,49

24.02.09

0,10

2,48

0,12

7,59

22.04.09

0,18

8,52

09.06.09

0,13

5,69

22.06.09

0,14

9,17

0,06

6,55

19.08 .09

0,09

5,12

24.09.09

0,04

8,85

22.10.09

0,05

8,48

\begin{tabular}{cccc}
\multicolumn{3}{c}{$n m$} & $\mathrm{~nm}$ \\
0,0132 & $\pm 0,0013$ & $\mathrm{~nm}$ \\
0,0203 & $\pm 0,0016$ & 7,13 \\
0,0218 & $\pm 0,0021$ & 6,78 \\
0,0191 & $\pm 0,0013$ & 5,76 \\
0,0193 & $\pm 0,0019$ & 6,63 \\
0,0145 & $\pm 0,0062$ & 6,39 \\
0,0099 & $\pm 0,0016$ & 6,21 \\
0,0107 & $\pm 0,0046$ & 7,11 \\
0,0044 & $\pm 0,0004$ & 6,73 \\
0,0057 & $\pm 0,0009$ & 6,60 \\
0,0039 & $\pm 0,0007$ & 6,90 \\
0,0120 & $\pm 0,0036$ & $\mathrm{~nm}$
\end{tabular}

Bougival

22.10.08

25.11.08

0,22

12,7

0,25

10,7

16.12 .08

0,15

11,2

0,21

6,42

24.02.09

0,17

13,3

0,17

38,4

22.04.09

12,6

09.06.09

0,25

11,5

22.06.09

12,6

0,22

8,29

19.08 .09

0,17

11,1

24.09.09

0,13

16,3

22.10.09

0,13

11,7

$0,0416 \stackrel{\mathrm{nm}}{ \pm} 0,0088$

$0,0509 \pm 0,0079$

$0,0416 \pm 0,0079$

$0,0503 \pm 0,0154$

$0,0232 \pm 0,0100$

$0,0162 \pm 0,0019$

$0,0147 \pm 0,0071$

$0,0319 \pm 0,0057$

$0,0164 \pm 0,0012$

$0,0181 \pm 0,0029$

$0,0143 \pm 0,0010$

$0,0309 \pm 0,0042$

$\mathrm{nm}$

$\mathrm{nm}$

$\mathrm{nm}$

9,25

11,4

8,64

8,25

11,1

$\mathrm{nm}$

11,8

9,61

9,97

$\mathrm{nm}$

Triel

22.10.08

0,39

17,5

0,32

17,2

$0,0347 \stackrel{\mathrm{nm}}{ \pm} 0,0137$

$\mathrm{nm}$

25.11.08

0,20

25,2

19.01 .09

13,9

$0,0729 \pm 0,0080$

$\mathrm{nm}$

0,32

$0,0727 \pm 0,0118$

8,10

0,21

8,07

24.03.09

0,26

$0,0780 \pm 0,0062$

9,63

0,33

5,95

22.04.09

12,8

0,31

$0,0464 \pm 0,0113$

7,69

$0,0376 \pm 0,0091$

12,1

15,4

22.06.09

7,98

0,30

$0,0275 \pm 0,0020$

9,00

0,38

18,0

19.08 .09

0,28

$0,0435 \pm 0,0031$

10,3

$0,0288 \pm 0,0026$

11,0

10,9

24.09.09

0,21

$0,0294 \pm 0,0027$

13,0

20,3

$0,0287 \pm 0,0053$

11,8

0,29

14,0

$0,0567 \pm 0,0073$

$\mathrm{nm}$

$\mathrm{nm}$

$\mathrm{nm}=$ non

measured

$<\mathrm{QL}=$ lower than

quantification limit 


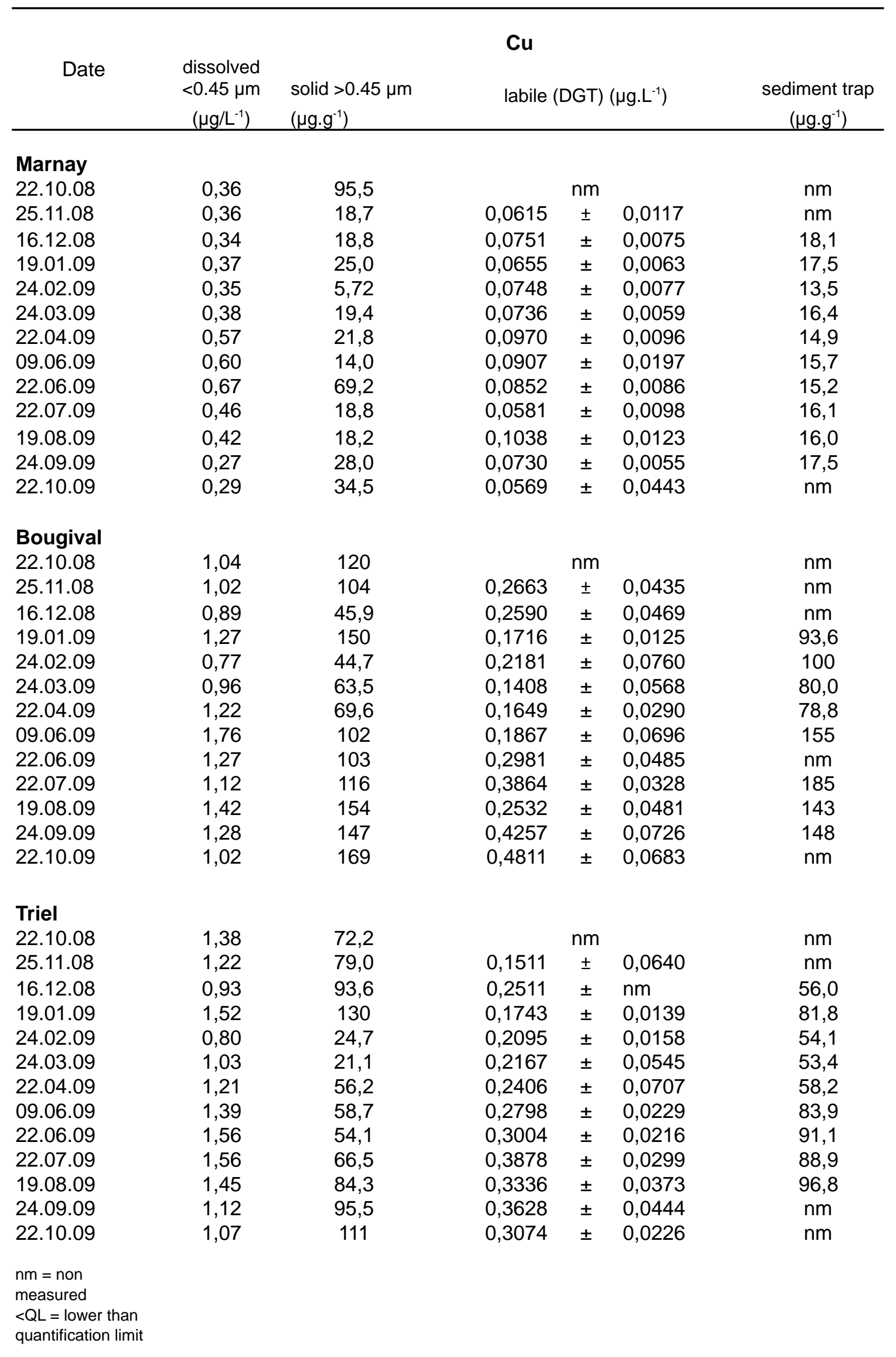


$\mathrm{Mn}$

Date

dissolved $<0.45$ solid $>0.45 \mu \mathrm{m}$

labile (DGT) $\left(\mu \mathrm{g} \cdot \mathrm{L}^{-1}\right)$

sediment trap

$\mu \mathrm{m}\left(\mu \mathrm{g} / \mathrm{L}^{-1}\right) \quad\left(\mu \mathrm{g} \cdot \mathrm{g}^{-1}\right)$

$\left(\mu \mathrm{g} \cdot \mathrm{g}^{-1}\right)$

Marnay

22.10.08

25.11.08

16.12 .08

19.01.09

24.02.09

24.03.09

22.04.09

09.06 .09

22.06.09

22.07.09

19.08 .09

24.09.09

22.10.09

2,20

761

2,60

658

1,51

2,73

593

444

1,64

130

2,55

417

3,19

793

2,45

422

3,01

394

1,82

343

2,43

379

1,44

798

1,81

910

$1,89 \stackrel{\mathrm{nm}}{ \pm} \quad 0,183$

$\mathrm{nm}$

$2,40 \pm 0,178$

$\mathrm{nm}$

$3,21 \pm 0,285$

441

$2,24 \pm 0,181$

425

$2,27 \pm 0,209$

334

$1,13 \pm 0,107$

311

$0,650 \pm 0,1857$

282

$0,787 \pm 0,1181$

268

$0,361 \pm 0,0277$

527

$0,406 \pm 0,0335$

456

$0,279 \pm 0,0755$

436

$1,14 \pm 0,876$

464

$\mathrm{nm}$

\section{Bougival}

22.10.08

25.11.08

7,01

972

8,01

917

16.12 .08

3,07

1035

19.01.09

8,68

514

24.02.09

6,97

1057

24.03.09

6,77

1282

22.04.09

7,40

1528

09.06 .09

10,7

817

17,4

1450

22.06.09

13,5

665

13,1

797

9.08.09

8,30

1762

22.10.09

8,89

1186

$\begin{array}{cccc} & \mathrm{nm} & & \mathrm{nm} \\ 4,99 & \pm & 1,171 & \mathrm{~nm} \\ 8,32 & \pm & 1,068 & \mathrm{~nm} \\ 7,18 & \pm & 1,312 & 532 \\ 7,82 & \pm & 2,211 & 679 \\ 3,72 & \pm & 1,758 & 372 \\ 2,06 & \pm & 0,391 & 1825 \\ 1,95 & \pm & 0,883 & 281 \\ 8,38 & \pm & 1,228 & \mathrm{~nm} \\ 2,66 & \pm & 0,572 & 633 \\ 3,49 & \pm & 0,351 & 642 \\ 2,27 & \pm & 0,327 & 644 \\ 6,55 & \pm & 0,824 & \mathrm{~nm}\end{array}$

Triel

22.10.08

17,7

1678

25.11.08

12,7

1911

16.12 .08

4,37

2209

19.01.09

13,2

1224

24.02.09

9,37

570

$11,2 \quad 484$

22.04 .09

11,6

1329

09.06 .09

17,6

1428

22.06.09

20,2

752

$27,6 \quad 2314$

$22,1 \quad 1097$

19.08.09

24.09.09

15,4

2208

22.10.09

15,8

1667

\begin{tabular}{lcl}
\multicolumn{3}{c}{$\mathrm{nm}$} \\
3,43 & \pm & 1,436 \\
9,82 & \pm & 1,083 \\
10,2 & \pm & 1,73 \\
9,93 & \pm & 0,741 \\
6,56 & \pm & 1,462 \\
4,56 & \pm & 1,172 \\
3,24 & \pm & 0,284 \\
9,38 & \pm & 0,687 \\
4,63 & \pm & 0,634 \\
4,71 & \pm & 0,373 \\
4,45 & \pm & 0,554 \\
9,65 & \pm & 1,670
\end{tabular}

$\mathrm{nm}$

$\mathrm{nm}$

594

502

513

780

437

414

872

966

948

$\mathrm{nm}$

$\mathrm{nm}$

$\mathrm{nm}=$ non

measured

$<\mathrm{QL}=$ lower than

quantification limit 
$\mathrm{Ni}$

Date

dissolved $<0.45$ solid $>0.45 \mu \mathrm{m}$

labile (DGT) $\left(\mu \mathrm{g} \cdot \mathrm{L}^{-1}\right)$

sediment trap

$\mu \mathrm{m}\left(\mu \mathrm{g} / \mathrm{L}^{-1}\right) \quad\left(\mu \mathrm{g} \cdot \mathrm{g}^{-1}\right)$

$\left(\mu \mathrm{g} \cdot \mathrm{g}^{-1}\right)$

\section{Marnay}

22.10.08

25.11.08

16.12 .08

19.01 .09

24.02.09

24.03.09

22.04.09

09.06 .09

22.06.09

22.07.09

19.08 .09

24.09.09

22.10.09

\section{Bougival}

22.10.08

25.11.08

16.12 .08

19.01.09

24.02.09

24.03.09

22.04.09

09.06 .09

22.06.09

22.07.09

19.08.09

24.09.09

22.10.09

\section{Triel}

22.10.08

25.11.08

16.12 .08

19.01.09

24.02.09

24.03.09

22.04.09

09.06 .09

22.06.09

22.07.09

19.08.09

24.09.09

22.10.09

$\mathrm{nm}=\mathrm{non}$

measured

$<\mathrm{QL}=$ lower than

quantification limit
83,5

23,7

32,0

26,4

13,8

19,9

23,8

25,4

9,13

20,5

33,8

28,5

35,2

36,7

27,3

32,1

20,9

36,0

33,9

30,3

26,3

27,3

26,2

38,5

32,7

40,5

0,94

2,74

2,43

1,96

2,21

2,04

2,11

2,59

2,34

2,36

2,17

1,79

1,49

1,96
47,8

18,4

59,5

30,2

21,5

12,9

30,1

29,3

20,6

39,5

38,5

30,0

41,5

$\begin{array}{cccc} & \mathrm{nm} & & \mathrm{nm} \\ 0,154 & \pm & 0,0155 & \mathrm{~nm} \\ 0,205 & \pm & 0,0171 & 26,2 \\ 0,202 & \pm & 0,0274 & 24,8 \\ 0,209 & \pm & 0,0154 & 20,5 \\ 0,195 & \pm & 0,0178 & 21,6 \\ 0,212 & \pm & 0,0356 & 20,5 \\ 0,173 & \pm & 0,0370 & 20,6 \\ 0,196 & \pm & 0,0227 & 21,6 \\ 0,095 & \pm & 0,0082 & 21,1 \\ 0,135 & \pm & 0,0184 & 20,6 \\ 0,116 & \pm & 0,0076 & 21,4 \\ 0,166 & \pm & 0,0444 & \mathrm{~nm}\end{array}$

$0,369 \stackrel{\mathrm{nm}}{ \pm} \quad 0,0287$

$0,446 \pm 0,0353$

$0,297 \pm 0,0523$

$0,322 \pm 0,0582$

$0,228 \pm 0,0982$

$0,177 \pm 0,0411$

$0,185 \pm 0,1641$

$0,324 \pm 0,0534$

$0,470 \pm 0,0656$

$0,321 \pm 0,0857$

$0,419 \pm 0,0478$

$0,458 \pm 0,0420$

$\mathrm{nm}$

$\mathrm{nm}$

$\mathrm{nm}$

31,2

38,8

27,8

26,2

40,2

$\mathrm{nm}$

37,0

28,7

31,4

$\mathrm{nm}$

$\begin{array}{cccc} & \mathrm{nm} & & \mathrm{nm} \\ 0,172 & \pm & 0,1870 & \mathrm{~nm} \\ 0,545 & \pm & 0,0412 & 28,0 \\ 0,465 & \pm & 0,0440 & 30,5 \\ 0,451 & \pm & 0,0308 & 21,2 \\ 0,426 & \pm & 0,0927 & 23,6 \\ 0,443 & \pm & 0,1258 & 25,2 \\ 0,578 & \pm & 0,0451 & 27,7 \\ 0,543 & \pm & 0,0446 & 27,2 \\ 0,752 & \pm & 0,0564 & 30,7 \\ 0,564 & \pm & 0,0534 & 29,3 \\ 0,681 & \pm & 0,0707 & \mathrm{~nm} \\ 0,796 & \pm & 0,0550 & \mathrm{~nm}\end{array}$

$\mathrm{nm}$

28,0

30,5

21,2

23,6

25,2

27,2

30,7

$\mathrm{nm}$

$\mathrm{nm}$ 
$\mathrm{Zn}$

Date

labile (DGT) $\left(\mu \mathrm{g} \cdot \mathrm{L}^{-1}\right) \quad$ sediment trap

Marnay
22.10.08

25.11.08

16.12 .08

19.01 .09

24.02.09

24.03.09

22.04.09

09.06 .09

22.06.09

22.07.09

19.08 .09

24.09.09

22.10.09

dissolved $<0.45$ solid $>0.45 \mu \mathrm{m}$ $\mu \mathrm{m}\left(\mu \mathrm{g} / \mathrm{L}^{-1}\right) \quad\left(\mu \mathrm{g} \cdot \mathrm{g}^{-1}\right)$

$\left(\mu \mathrm{g} \cdot \mathrm{g}^{-1}\right)$

\section{Bougival}

22.10.08

25.11.08

16.12 .08

19.01 .09

24.02.09

24.03.09

22.04.09

09.06 .09

22.06 .09

22.07.09

19.08 .09

24.09.09

22.10.09

$\begin{array}{cc}<\mathrm{QL} & 45 \\ 2,67 & 128 \\ <\mathrm{QL} & 171 \\ 9,77 & 188 \\ <\mathrm{QL} & 71 \\ 3,94 & 395 \\ 2,26 & 451 \\ 2,61 & 140 \\ 2,53 & 134 \\ 1,82 & 185 \\ 1,24 & 713 \\ <\mathrm{QL} & 219 \\ 2,43 & 417\end{array}$

$n m$
$0,444 \quad \pm \quad 0,0794$
$1,49 \pm 0,3041$

$\mathrm{nm}$

$1,49 \pm 0,3041$
$0,988 \pm 0,6036$

$0,836 \pm 0,2054$

$0,159 \pm 0,2726$

$0,756 \pm 0,3556$

$0,693 \pm 0,1770$

$0,000 \pm 0,0000$

$0,365 \pm 0,2242$

$\mathrm{nm}$

149

141

126

106

108

109

$0,274 \pm 0,0185$

125

$0,115 \pm 0,0942$

$0,578 \pm 0,1292$

117

113

122

$\mathrm{nm}$

\section{Triel}

22.10.08

6,68

465

24,1

410

7,35

336

642

15,1
$4,39 \quad 480$

$6,02 \quad 567$

$6,28 \quad 645$

$9,76 \quad 380$

$6,22 \quad 409$

$3,55 \quad 383$

$4,77 \quad 671$

$3,28 \quad 542$

$3,65 \quad 508$

$\begin{array}{cc}\mathrm{nm} & \mathrm{nm} \\ 2,64 \pm 0,366 & \mathrm{~nm} \\ 3,13 \pm 0,469 & \mathrm{~nm} \\ 1,79 \pm 0,382 & 439 \\ 2,47 \pm 0,517 & 506\end{array}$

$0,402 \pm 0,778 \quad 307$

$0,352 \pm 0,128 \quad 307$

$1,51 \pm 0,824 \quad 694$

$2,07 \pm 0,329 \quad \mathrm{~nm}$

$2,49 \pm 0,378 \quad 629$

$1,69 \pm 0,805 \quad 505$

$1,83 \pm 0,329 \quad 515$

$2,34 \pm 0,384 \mathrm{~nm}$

25.11.08

$7,08 \quad 351$

351
363

$\begin{array}{lc}14,6 & 363 \\ 3,90 & 1402\end{array}$

16.12 .08

14,6

608

19.01 .09
24.02 .09

3,47

232

4,72

135

22.04.09

6,15

434

09.06 .09

7,88

302

22.06.09

9,45

43

6,72

350

22.07 .09
19.08 .09

4,53

522

4,10

399

22.10.09

9,00

256

\begin{tabular}{l}
\multicolumn{3}{c}{$\mathrm{nm}$} \\
$1,46 \pm 0,704$ \\
$3,57 \pm 0,333$ \\
$2,79 \pm 0,456$ \\
$3,74 \pm 0,270$ \\
$1,44 \pm 0,291$ \\
$1,55 \pm 0,472$ \\
$2,89 \pm 0,262$ \\
$2,68 \pm 0,207$ \\
$3,07 \pm 0,229$ \\
$2,42 \pm 0,186$ \\
$2,37 \pm 0,386$ \\
$3,06 \pm 0,398$
\end{tabular}

$\mathrm{nm}$

$\mathrm{nm}$

299

408

226

225

249

342

387

395

415

$\mathrm{nm}$

$\mathrm{nm}$

$\mathrm{nm}=\mathrm{non}$

measured

$<\mathrm{QL}=$ lower than

quantification limit 


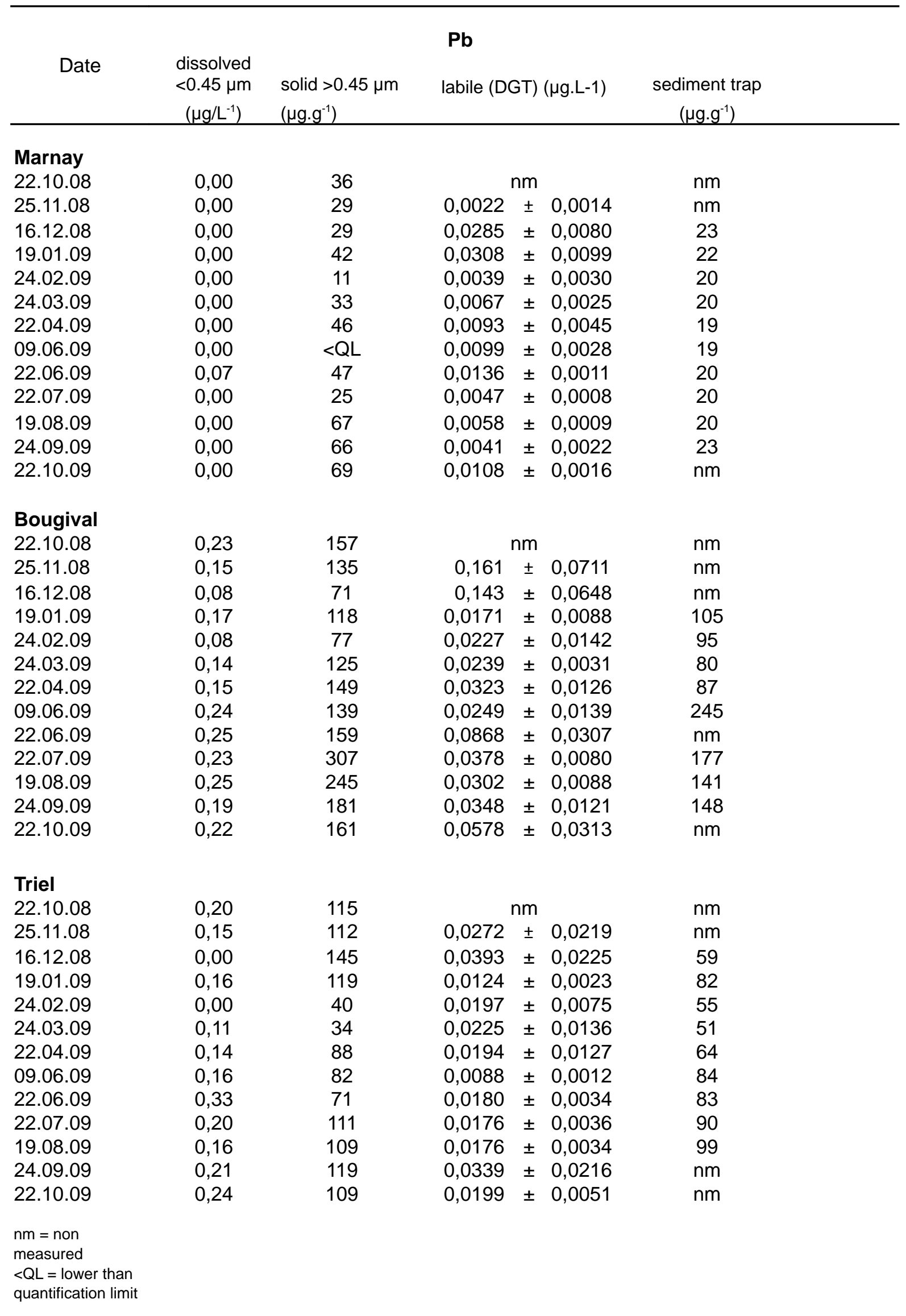

